\title{
UM RETRATO DAS PESQUISAS SOBRE LIVROS DIDÁTICOS DE SOCIOLOGIA NO BRASIL
}

\author{
Cristiano das Neves BODART ${ }^{1}$
}

RESUMO: O artigo analisa a produção científica brasileira, especialmente os artigos que toma como objeto, ou fonte de pesquisa, os livros didáticos (ou manuais) de Ciências Sociais (Sociologia, Antropologia e Ciência Política). São analisados aspectos constituintes dessa produção, tais como perfil dos autores e das autoras, os focos das pesquisas, seus métodos, suas técnicas e principais referências. Fica evidenciada a expansão do volume de artigos publicados a partir de 2014, tendo o envolvimento maior de pesquisadoras doutoras em Sociologia. Observou-se que os artigos se voltam prioritariamente à análise interna dos livros didáticos, mais especificamente à análise de conteúdo, havendo uma reduzida preocupação com reflexóes metodológicas do campo da manualística. As referências são variadas, não figurando uma rede de citação interna. É explicitado que a figuração do manual escolar como objeto de análise está relacionada às dinâmicas de produção e ao consumo desse recurso didático, tendo o Plano Nacional do Livro Didático (PNLD) uma importante participação nessa dinâmica, e ao recente desenvolvimento do subcampo de pesquisa sobre o ensino de Sociologia.

PALAVRAS-CHAVES: livros didáticos; manuais escolares; ciências sociais; sociologia.

\section{A PICTURE OF RESEARCH ON SOCIOLOGY TEXTBOOKS IN BRAZIL}

ABSTRACT: The article analyzes the Brazilian scientific production, especially the articles, which takes as object or source of research and textbooks (or manuals) of Social Sciences (Sociology, Anthropology and Political Science). Constituent aspects of this production are

\footnotetext{
1 Universidade Federal de Alagoas (Ufal), Centro de Educação, Maceió - AL - Brasil. Docente do programa de Pós-graduação em Sociologia. Universidade de São Paulo (USP), São Paulo - SP - Brasil. Doutor em Sociologia. Vice-presidente da Associação Brasileira de Ensino de Ciências Sociais (gestões 2018-2020 e 2021-2022). Fundador e editor do Café com Sociologia. ORCID: http://orcid.org/0000-0002-2195-2145. cristianobodart@gmail.com.
} 
analyzed, such as the authors and authors profile, the research focuses, their methods, their techniques and main references. It is evident the expansion of the volume of articles published since 2014, being the involvement of researchers with a major doctorate in Sociology. It was observed that the articles focus primarily on the internal analysis of textbooks, more specifically content analysis and a reduced concern with methodological reflections in the field of manual writing. The references are varied, not including an internal citation network. It is explained that the figuration of the school manual as an object of analysis is related to the dynamics of production and consumption of this didactic resource, with the National Textbook Plan (PNLD) an important participation in this dynamic, and to the recent development of the research subfield on Sociology teaching.

KEYWORDS: textbooks; school manuals; social sciences; sociology.

\section{Introdução}

Em geral, as pesquisas que se caracterizam como estado da arte são produzidas quando se supóe que uma área, campo ou subcampo de pesquisa, está em expansão ou se consolidando. As pesquisas denominadas estado da arte têm, em geral, por objetivo, apresentar um panorama do que já foi produzido para auxiliar pesquisadores em diversos aspectos, entre eles: a) compreender a configuração do campo, área ou subcampo; b) examinar os avanços conquistados pelas pesquisas já publicadas; c) apreender as dinâmicas sociais do campo, área ou subcampo, tais como as redes entre pesquisadores, os espaços ocupados e o perfil dos autores; d) identificar as principais referências mobilizadas; e) observar os espaços produtores e divulgadores de conhecimento; f) identificar aspectos ainda não explorados e; g) identificar os principais tipos e focos das pesquisas. Pesquisas do tipo estado da arte contribuem para que a produção científica não "ande em círculos", antes, para que avance em direções pouco ou não exploradas.

Quando se trata do ensino de Sociologia, parece haver uma aposta de que estamos diante de uma constituição de um subcampo de pesquisa, ainda que em formação, o que tem fomentado a produçáo de diversos estados da arte com variados recortes. Dentre elas, destacam-se as pesquisas desenvolvidas por Handfas (2011, 2016), Handfas e Maçaira (2012), Bodart e Cigales (2017), Bodart e Souza (2017), Brunetta e Cigales (2018), Bodart e Tavares (2020), Engerroff, Cigales e Tholl (2017) e Engerroff (2017). Esses trabalhos atestam que estamos diante de um processo de constituição e expansão do subcampo do ensino de Sociologia. Esta pesquisa soma-se a esses trabalhos, ao ter por 
recorte de análise os artigos publicados em periódicos científicos, que tomam os manuais/livros didáticos de Sociologia como objeto ou fonte de pesquisa. Tal intento se dá pela necessidade de examinar o desenvolvimento da manualística no subcampo de pesquisa do ensino de Sociologia no Brasil.

Chamamos a atenção para o título, "Um retrato das pesquisas sobre livros didáticos de Sociologia no Brasil”, o qual traz alguns aspectos que delineia esta pesquisa. O termo "retrato" refere-se ao fato de reconhecermos duas questóes importantes: a) a despeito de estarmos manuseando dados aparentemente objetivos, há aspectos subjetivos que orientam o recorte da pesquisa, sendo eles a escolha por artigos e as categorizaçóes realizadas; trata-se, portanto, de um olhar possível entre tantos outros. O uso da expressão "retrato" faz alusão ao congelamento da cena em um dado tempo e espaço, no caso da pesquisa, os artigos indexados no Google Scholar no dia da coleta, em 30 de dezembro de 2020; b) trata-se de uma pesquisa de estado da arte que considerou os artigos que realizam análises de livros didáticos/manuais brasileiros e; c) ainda que tenhamos nos voltado à possibilidade de encontrarmos artigos que analisam livros didáticos (ou manuais) das Ciências Sociais, adotamos o termo Sociologia por ser esse utilizado no ensino secundário brasileiro.

Pela tipologia deste artigo - estado da arte - e pelos limites de espaço impostos a um artigo, a nossa principal preocupação é apresentar um mapeamento da produção de artigos voltados à análise de livros didáticos de Ciências Sociais/Sociologia, embora ao longo do texto realizamos algumas análises do corpus da pesquisa que julgamos relevantes.

O artigo está estruturado em quatro partes, além desta introdução e das consideraçóes finais. A primeira parte é destinada aos procedimentos metodológicos adotados para este estado da arte. A segunda é dedicada a analisar os artigos e seus espaços de produção. Na terceira parte, nos voltamos para as referências que fundamentam os artigos e, por fim, na quarta parte, observamos aspectos relacionados ao perfil dos autores.

\section{Procedimentos metodológicos}

Para identificar a produção científica brasileira, que se volta aos livros de Sociologia, realizamos um levantamento de artigos indexados no Google Scholar. Optamos por realizar a busca no Google Scholar por ser possível coletar artigos publicados em revistas com indexadores ou não, o que torna a busca mais completa. Usamos 8 descritores, os quais foram: "Sociologia manuais escolares"; "Sociologia livro didático"; "livro didático Antropologia”; "manuais de 
Antropologia"; "livro didático Ciência Política"; "manuais de Ciência Política", "manuais de Ciências Sociais" e "livro didático Ciências Sociais". Para a seleção dos resultados foram lidos os títulos e os resumos dos artigos que apareceram nas buscas. Foram considerados apenas os artigos que analisam livros didáticos (ou manuais) de Sociologia, de Antropologia, de Ciência Politica ou de Ciências Sociais, publicados em periódicos científicos de língua portuguesa.

Filtrados os resultados a partir dos títulos e resumos, encontramos 52 artigos publicados em periódicos científicos (ver anexo 1), que tomam os manuais/ livros didáticos de Ciências Sociais/Sociologia como objeto ou fonte de pesquisa. O levantamento foi realizado em 30 de dezembro de 2020. Para sistematizar os dados e suas variáveis, utilizamos o Microsoft Excel. As variáveis, apresentadas no Quadro 1, foram definidas a partir dos objetivos propostos pela pesquisa.

Quadro 1 - Fontes e variáveis que compóem o corpus da pesquisa.

\begin{tabular}{|c|c|c|c|c|c|c|}
\hline Fontes & \multicolumn{5}{|c|}{ Variáveis } \\
\hline Revista & Título do artigo & Revista & $\begin{array}{c}\text { Regiáo da } \\
\text { revista }\end{array}$ & Ano & \multicolumn{2}{|c|}{$\begin{array}{c}\text { Qualis nas áreas de } \\
\text { Educaçáo e Sociologia* }\end{array}$} \\
\hline Artigo & $\begin{array}{c}\text { Recorte de } \\
\text { análise }\end{array}$ & \multicolumn{2}{|c|}{ Método prioritário } & Foco & \multicolumn{2}{|c|}{ Referências } \\
\hline $\begin{array}{c}\text { Currículo } \\
\text { Lattes }\end{array}$ & $\begin{array}{c}\text { Nome dos/ } \\
\text { as autores/as }\end{array}$ & $\begin{array}{c}\text { Link para o } \\
\text { Currículo } \\
\text { Lattes }\end{array}$ & $\begin{array}{c}\text { Curso de } \\
\text { graduação }\end{array}$ & $\begin{array}{c}\text { Maior } \\
\text { titulação }\end{array}$ & Área da titulação & $\begin{array}{c}\text { Experiência na } \\
\text { educaçáa básica }\end{array}$ \\
\hline
\end{tabular}

Nota: A linha três se repetiu proporcionalmente ao número de autores do artigo. *Para identificar o Qualis dos periódicos utilizamos a Plataforma Sucupira, espaço online de consulta disponibilizado pela CAPES ${ }^{2}$.

Fonte: Elaboração própria.

O levantamento do estado da arte vem apresentando uma importante contribuição para a compreensão do subcampo de pesquisa do ensino de Sociologia, o qual vem se ampliando nos últimos anos, reflexo da presença da Sociologia no ensino médio, fato que impactou positivamente na ampliação do número de licenciaturas em Ciências Sociais/Sociologia, a realização de eventos especializados na temática, a publicação de dossiês, o surgimento da Associação Brasileira de Ensino de Ciências Sociais (Abecs), bem como a maior proximidade das entidades científicas com o tema. O conceito de subcampo adotado tem sua origem no conceito de campo, de Pierre Bourdieu (1993), tratando-se de uma

2 Disponível em: https://sucupira.capes.gov.br/sucupira/public/consultas/coleta/veiculoPublicacaoQualis/lista ConsultaGeralPeriodicos.jsf. Acesso em: 07 set. 2021. 
esfera social, uma parte do campo que constitui um sistema de posiçóes sociais, uma espécie de microcosmo do espaço social, estando marcado por disputas de interesses específicos, possuindo regras próprias, autonomia relativa em relação a outros campos, no caso do subcampo do ensino de Sociologia, dos campos científico e educacional ${ }^{3}$.

\section{O locus de publicização dos artigos analisados}

A despeito de existirem outros locus de divulgação científica, tais como livros, congressos, simpósios e comunicações, o periódico científico é um espaço privilegiado pela visualização que promove e por ser utilizado como uma das principais variáveis de avaliação da "produtividade" do pesquisador e da pesquisadora, principalmente se forem vinculados à pós-graduação. Assim, parte importante das pesquisas realizadas com sucesso no país transformam-se em artigos científicos divulgados em periódicos acadêmicos. Por esse motivo, publicar em revistas acaba sendo um dos principais objetivos dos pesquisadores e pesquisadoras, já que a publicação do artigo "sela a qualidade" da pesquisa, sobretudo se o periódico for qualificado nos estratos superiores no Qualis-Periódicos. Esse fato justifica o recorte adotado.

No conjunto dos 52 artigos identificados observamos que eles foram publicados em 29 periódicos acadêmicos brasileiros. A Tabela 1 apresenta os dados coletados, referentes a essas revistas.

Tabela 1 - Periódicos que publicaram artigos que tomam os manuais/livros didáticos de Sociologia como objeto ou fonte de pesquisa, por Qualis, número de artigos e região sede.

\begin{tabular}{lccc}
\hline Periódico & $\begin{array}{c}\text { Qualis }{ }^{*}- \\
\text { Educação / } \\
\text { Sociologia }\end{array}$ & $\begin{array}{c}\text { No de } \\
\text { artigos }\end{array}$ & $\begin{array}{c}\text { Região sede } \\
\text { do periódico }\end{array}$ \\
\hline Em tese (UFSC) & C/B4 & 8 & Sul \\
\hline Perspectiva Sociológica (CPII) & $-/-$ & 7 & Sudeste \\
\hline Revista Brasileira de História da Educação (UEM) & A1/B2 & 4 & Sul \\
\hline $\begin{array}{l}\text { Cadernos da Associaçáo Brasileira de Ensino de Ciências Sociais } \\
\text { (ABECS) }\end{array}$ & $-/-$ & 3 & Sudeste \\
\hline
\end{tabular}

3 Para saber mais sobre a construção conceitual e empírica do subcampo do ensino de Sociologia, ver Bodart (2019) e Mocelin (2020). 


\begin{tabular}{|c|c|c|c|}
\hline Periódico & $\begin{array}{l}\text { Qualis* }^{*} \\
\text { Educaçáo / } \\
\text { Sociologia }\end{array}$ & $\begin{array}{l}N^{\circ} \text { de } \\
\text { artigos }\end{array}$ & $\begin{array}{l}\text { Regiáo sede } \\
\text { do periódico }\end{array}$ \\
\hline Revista HISTEDBR On-line (Unicamp) & $\mathrm{B} 1 / \mathrm{B} 4$ & 3 & Sudeste \\
\hline Ciências Sociais Unisinos (Unisinos) & $\mathrm{B} 5 / \mathrm{A} 2$ & 2 & Sul \\
\hline Revista Café com Sociologia (independente) & $\mathrm{B} 5 / \mathrm{B} 5$ & 2 & Nordeste \\
\hline Sociologias Plurais (UFPR) & $\mathrm{B} 5 / \mathrm{B} 5$ & 2 & Sul \\
\hline Estudos de Sociologia (UFPE) & $\mathrm{B} 5 / \mathrm{B} 1$ & 1 & Nordeste \\
\hline Estudos de Sociologia (UNESP) & $\mathrm{B} 1 / \mathrm{B} 1$ & 1 & Sudeste \\
\hline Interfaces Científicas - Educação (Grupo Tiradentes) & $\mathrm{B} 2 /-$ & 1 & Nordeste \\
\hline Alabastro (FESPSP) & $-/ B 5$ & 1 & Sudeste \\
\hline Cadernos de Estudos Sociais (Fundaj) & $\mathrm{B} 5 / \mathrm{C}$ & 1 & Nordeste \\
\hline Colloquium Socialis (Unoeste) & $-1-$ & 1 & Sudeste \\
\hline Criativa educativa (UFSCar) & $\mathrm{B} 3 /-$ & 1 & Sudeste \\
\hline Em Debate (UFASC) & $\mathrm{B} 4 / \mathrm{B} 5$ & 1 & Sul \\
\hline Mediaçôes (UEL) & $\mathrm{B} 1 / \mathrm{B} 1$ & 1 & Sul \\
\hline REVES - Revista Relações Sociais (UFV) & $-1-$ & 1 & Sudeste \\
\hline Revista Ártemis (UFPB) & $\mathrm{B} 5 / \mathrm{B} 3$ & 1 & Nordeste \\
\hline $\begin{array}{l}\text { Revista Brasileira de História \& Ciências Sociais } \\
\text { (FURG) }\end{array}$ & B1/B3 & 1 & Sul \\
\hline Revista Brasileira de Sociologia - RBS (SBS) & $\mathrm{A} 2 / \mathrm{B} 4$ & 1 & Centro-Oeste \\
\hline Revista Inter-Legere (UFRN) & $\mathrm{B} 5 / \mathrm{B} 4$ & 1 & Nordeste \\
\hline $\begin{array}{l}\text { Revista Interdisciplinar em Estudos de Linguagem } \\
\text { (IFSP) }\end{array}$ & $-/-$ & 1 & Sudeste \\
\hline Revista Pós-Ciências Sociais (UFMA) & $\mathrm{B} 1 / \mathrm{B} 1$ & 1 & Nordeste \\
\hline Revista Relegens Thréskeia (UFPR) & $\mathrm{B} 5 /-$ & 1 & Sul \\
\hline Revista Urutágua (UEM) & $\mathrm{B} 5 / \mathrm{B} 5$ & 1 & Sul \\
\hline Saberes em Perspectiva (Uesb) & $\mathrm{C} / \mathrm{B} 5$ & 1 & Nordeste \\
\hline Teoria e Cultura (UFJF) & $\mathrm{C} / \mathrm{B} 2$ & 1 & Sudeste \\
\hline Teoria e Prática da Educação (UEM) & $\mathrm{B} 2 / \mathrm{B} 4$ & 1 & Sul \\
\hline
\end{tabular}

Nota: Avaliação Qualis-Periódico, quadriênio 2013-2016. Consulta em: 30 dez. 2020.

Fonte: Elaboração própria com base em levantamento realizado no Google Scholar, em 30 dez. 2020. 
Por meio da Tabela 1 podemos observar que o maior volume de artigos sobre análises de livros didáticos (ou manuais) deram-se nos periódicos "Em tese" (8), "Perspectiva Sociológica" (7) e "Revista Brasileira de História da Educação" (4), o que se explica pelos seguintes motivos: a revista "Perspectiva Sociológica" é voltada quase que exclusivamente às publicações sobre o ensino de Sociologia. Já as outras duas revistas publicaram dossiês sobre manuais escolares, edições em que encontramos esses artigos. Os dados nos possibilitam inferir que a publicação de artigos sobre o tema em questão não está concentrada em poucos periódicos, o que pode ser favorável à divulgação do tema. Por outro lado, evidencia que os periódicos náo recepcionam recorrentemente artigos sobre o tema em questão.

Segundo Brunetta e Cigales (2018), até o ano de 2018 haviam sido publicados 18 dossiês sobre o ensino de Sociologia no Brasil. Desses, 2 foram sobre livros didáticos de Sociologia. O fato de notarmos a presença de poucos dossiês sobre livros didáticos (ou manuais) de Sociologia publicados é um indicativo de haver, até o momento, uma incipiente rede de pesquisadores e pesquisadoras que se dedicam ao tema.

Dentre os 29 periódicos, apenas 4 (13,7\%) estão ligados às instituiçóes privadas de ensino; em alguma medida isso é reflexo da pouca participaçáo do setor privado na produção de ciência no Brasil. Examinando a produção de artigos publicados em revistas de estratos superiores na avaliação Qualis-Periódicos, Bodart e Tavares (2020) fizeram essa mesma constatação. Em 2017, Bodart e Souza (2017) já haviam destacado o papel proeminente das universidades públicas, notando que todos os autores e autoras que haviam publicado artigos em dossiês sobre o ensino de Sociologia estavam a elas vinculados.

Nos chama a atenção o fato de apenas 9 artigos, dos 52, terem sido publicados em periódicos qualificados nos estratos superiores da avaliação QualisPeriódicos. Considerando a área de Sociologia esse número é ainda menor, apenas 5 artigos, dos 52 publicados. Tais dados apontam para a reduzida recepção do tema em espaços de maior prestígio social; a despeito da temática mais geral - ensino de Sociologia - vir ganhando espaço nesses periódicos (BODART; SOUZA, 2017).

O Gráfico 1 nos possibilita observar melhor as regiōes sedes dos periódicos. 
Gráfico 1 - Periódicos, por regiáo, que publicaram artigos científicos que tomam os manuais/livros didáticos de Sociologia como objeto ou fonte de pesquisa.

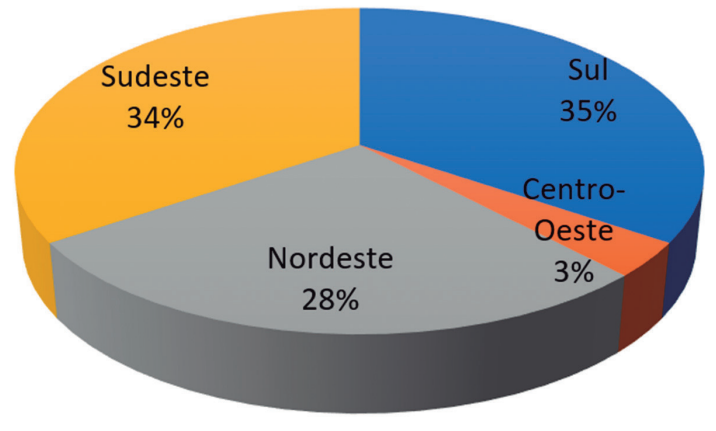

Fonte: Elaboração própria, com base em levantamento realizado no Google Scholar, em 30 dez. 2020.

Nota-se, por meio do Gráfico 1, que a região Centro-Oeste é sede de apenas 3\% dos periódicos em que os artigos foram publicados. Nos chama atenção a ausência de periódicos localizados na região Norte. A participação reduzida dessa regiáo também é constatada em outros estudos do subcampo do ensino de Sociologia, tais como aqueles realizados por Bodart e Cigales (2017) e Bodart e Tavares (2020). A maior parte dos periódicos que publicaram os artigos sobre o tema em questáo tem suas sedes nas regióes Sudeste (34\%) e Sul (35\%), respectivamente; o que pode ser explicado pelo maior volume de instituiçóes e periódicos ali localizados, fruto do histórico processo concentrado de institucionalização das Ciências Sociais (BODART; TAVARES, 2019). No estado da arte das teses e dissertaçóes sobre o ensino de Sociologia, Bodart e Cigales (2017) também observaram a maior participação dessas regióes; o mesmo foi notado em relação às sedes das revistas que publicaram dossiês sobre o ensino de Sociologia (BODART; SOUZA, 2017). O conjunto das pesquisas nos apontam que a concentração da produção acompanha a lógica da espacialização dos cursos de Ciências Sociais.

\section{Alguns aspectos dos artigos analisados}

Como já destacado, a base de dados produzida a partir de nossa metodologia encontrou 52 artigos. O primeiro artigo encontrado foi publicado em 2001 e o segundo em 2007; ambos de mesma autoria e analisando manuais de Sociologia publicados entre os anos de 1931 e 1948 . O terceiro artigo foi publi- 
cado em 2010 e analisou as produçôes em dois momentos históricos: 1935 e 1989. O quarto, também publicado em 2010, analisou manuais de Sociologia de 1923 a 1946. Nota-se que os primeiros artigos publicados voltaram-se para a história e institucionalização da Sociologia. Nessa mesma direção, Bodart e Cigales (2017) atestaram que a preocupação com a institucionalização da Sociologia e sua história foi marcante nas primeiras teses e dissertaçóes publicadas sobre o ensino de Sociologia no Brasil.

O Gráfico 2 apresenta a evolução do volume de artigos publicados, que analisam livros didáticos (ou manuais) de Sociologia.

Gráfico 2 - Evolução no número de artigos científicos, que tomam os manuais/livros didáticos de Sociologia como objeto ou fonte de pesquisa.

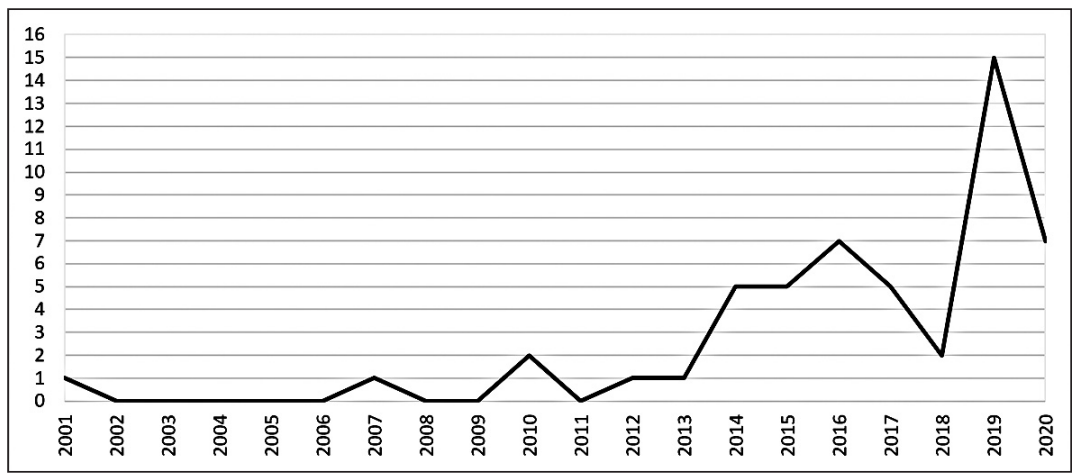

Fonte: Elaboração própria, com base em levantamento realizado no Google Scholar, em 30 dez. 2020.

O Gráfico 2 evidencia que são recentes os estudos que tomam os livros didáticos (ou manuais) de Sociologia como objeto de estudo ou como artefato histórico. Destacaram Brunetta e Cigales (2018) que dentre os artigos que compunham os dossiês sobre o ensino de Sociologia até então publicados, apenas $4,9 \%$ tratavam do livro didático de Sociologia. No exame dos artigos sobre a História do Ensino de Sociologia, Engerroff, Cigales e Tholl (2017), notaram um incremento na produção a partir de 2014. Se no estado da arte realizado por Handfas e Maçaira (2014) não foram identificadas teses e dissertaçóes em torno do livro didático de Sociologia, em levantamentos mais recentes (BODART; CIGALES, 2017; ENGERROFF, 2017; BODART; SOUZA, 2017), tal tema aparece em expansáo a partir de 2014, o que aqui também identificamos.

Por hipótese apontamos, ao menos, cinco motivos interligados: a) presença intermitente da Sociologia no ensino secundário brasileiro b) a participação 
da Sociologia no Plano Nacional do Livro Didático (PNLD) a partir de 2012; c) a expansão do subcampo de pesquisa do ensino de Sociologia; d) a recente expansão das licenciaturas em Ciências Sociais (BODART; TAVARES, 2018); e e) uma reduzida produção e circulação de manuais de Sociologia entre os anos de 1950 e 2012.

Engerroff (2017), ao observar a evolução de teses e dissertaçóes sobre livro didático a partir de 2014, apontou como hipótese explicativa a entrada da Sociologia no PNLD, em 2012. A mesma explicação foi exposta por Handfas (2016) em seu balanço dos papers apresentados no Grupo de Trabalho (GT) "Livros didáticos de Sociologia", no IV Encontro Nacional de Ensino de Sociologia da Educação Básica (ENESEB), em 2015. Inclusive, o que motivou a criação do GT "Livros didáticos de Sociologia" no ENESEB, em 2013, "foi a entrada da disciplina, desde 2012, no Programa Nacional do Livro Didático PNLD"; atestaram seus proponentes, Handfas e Santos (2013).

Os períodos de maior produção ou circulação de manuais de Sociologia deram-se entre 1930 e 1950 e após 2014, o que explica-se, respectivamente, a) pela intermitente presença obrigatória da Sociologia no ensino secundário (1929-1942 e 2008 em diante) e a criação de cursos de Ciências Sociais no Brasil (em 1933); e b) pela reintrodução, a partir de 2008, da Sociologia nas escolas e a inclusão desse componente curricular no PNLD, nos anos de 2012, 2015 e 2018.

Entre 1950 e 2012, a produção e a circulação de obras de Sociologia esteve voltada quase que exclusivamente para os acadêmicos (o mais próximo do que podemos denominar "livro didático" eram os poucos títulos de introdução à Sociologia). O comportamento na produção editorial observado no Brasil nos leva à hipótese de que a pesquisa de manualística é potente em contribuir para a compreensão da institucionalização da Sociologia no Brasil. Contudo, tal compreensão demanda um recorte analítico, que considere tanto os aspectos internos quanto externos aos livros didáticos (ou manuais). Chamamos análise interna aquela voltada para "dentro" do manual (conteúdos, discursos, estrutura, didática, elementos pré-textuais etc.). Por análise externa, aquela que considera os contextos (político, econômico, cultural, editorial, educacional, legislativo etc.) que envolvem a produção, o consumo e a circulação das obras. Ambos os recortes são importantes, embora com potencialidades diferentes. A Tabela 2 apresenta, em números e percentuais, os recortes analíticos dos 52 artigos. 
Tabela 2 - Recortes analíticos dos artigos científicos, que tomam os manuais/ livros didáticos de Sociologia como objeto ou fonte de pesquisa.

\begin{tabular}{c|c|c|c|c}
\hline Recorte & Interna & Externa & Interna e externa & Total \\
\hline Número & 38 & 7 & 8 & 52 \\
\hline Percentual & 73 & 13,4 & 15,3 & 100 \\
\hline
\end{tabular}

Fonte: Elaboração própria, com base em levantamento realizado no Google Scholar, em 30 dez. 2020.

Nota-se que as pesquisas em torno dos livros didáticos de Sociologia adotam, prioritariamente, a análise interna (73\%) dos livros didáticos (ou manuais) de Sociologia. Isso pode ter relação ao interesse em identificar o que está sendo ensinado na disciplina de Sociologia, o que se relaciona a não consolidação de um conjunto de temas no currículo; algo que deve ser explorado em pesquisas futuras. Se por um lado temos um volume significativo de trabalhos que visam analisar o interior dos livros didáticos, por outro, ainda carecemos de mais análises que contextualizem a produção, os usos, os conteúdos, os discursos e a circulação desses livros didáticos (ou manuais) às dimensôes políticos, culturais, educacionais, editoriais, econômicas etc. Os dados levantados nesta pesquisa apontam que as pesquisas envolvendo livros didáticos de Sociologia são pouco contextualizadas aos seus espaços de inserção. O Gráfico 3 apresenta a evolução dessas pesquisas por recorte analítico.

Gráfico 3 - Evolução no número de artigos científicos, que tomam os manuais/livros didáticos de Sociologia como objeto ou fonte de pesquisa, por tipo de recorte analítico.

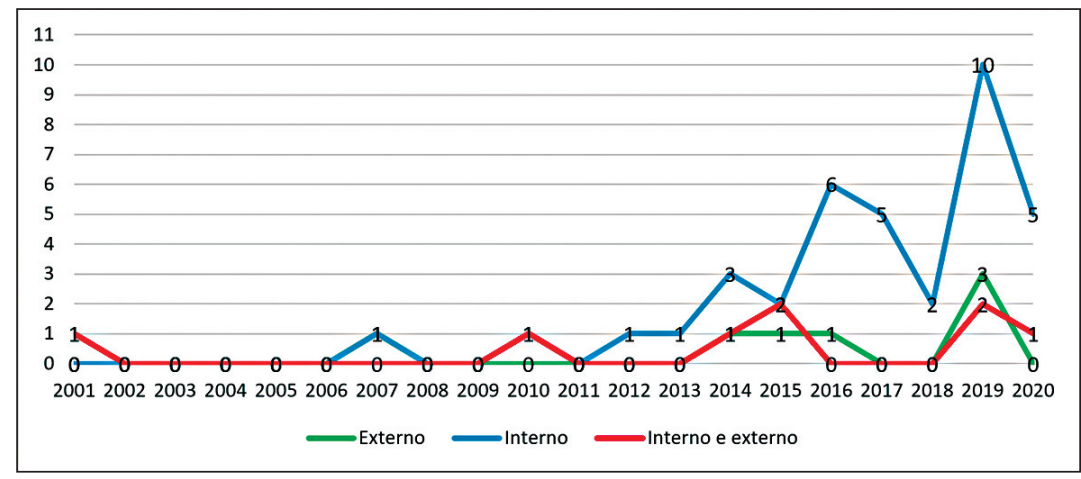

Fonte: Elaboração própria, com base em levantamento realizado no Google Scholar, em 30 dez. 2020 
Destacamos que dos 4 primeiros artigos publicados, 3 realizam análises internas e externas dos manuais (recortes analíticos), enquanto 1 se voltou à análise interna. Destacam-se, no conjunto dos artigos, um maior número de artigos que se voltam ao interior dos livros didáticos de Sociologia, sobretudo a partir de 2014. Nos anos seguintes às ediçôes do PNLD de 2015 e 2018 observamos um volume significativo de artigos publicados. Entre 2019 e 2020, foram publicados 2 dossiês sobre livros didáticos de Sociologia.

Destacou Batista (1999) que a investigação em torno do livro didático no Brasil foi tomada como uma preocupação menor. No caso particular dos livros didáticos de Sociologia, considerando a sua reduzida presença nas escolas antes dos anos 2000 e o fato da disciplina não ser amplamente ofertada no ensino básico, nos leva a crer que tornou o interesse da comunidade acadêmica por esse recurso didático ainda menor. Ou seja, o objeto de pesquisa até então "não se mostrava” e, por isso, poucos pesquisadores se voltavam para ele. $\mathrm{O}$ primeiro trabalho que temos notícia de ter examinado nos manuais de Sociologia é a dissertação de mestrado, defendida na Faculdade de Educação da Universidade de Sáo Paulo (USP), por Olavo Machado (1996), e intitulada O ensino de Ciências Sociais na escola média.

Importa destacar que não encontramos artigos que analisam livros didáticos (ou manuais) de Antropologia ou de Ciência Política, nem mesmo voltados ao ensino superior. $\mathrm{O}$ que encontramos foram artigos que, examinando livros didáticos de Sociologia contemplados no PNLD, buscaram observar a presença da Ciência Política (2 artigos) e da Antropologia (2 artigos). Também não identificamos artigos voltados à análise de livros didáticos de Ciências Sociais para o ensino fundamental.

Como destacou Choppin (2004), o livro didático é resultado de contextos socio-históricos, que apresentam variadas funçóes, tais como: a) de caráter referencial, ao trazer conteúdos; b) de caráter instrumental, ao apresentar-se como ferramenta de ensino-aprendizagem; c) de caráter ideológico, trazendo inscritas visóes de mundo; d) de caráter político, por trazer ideologias e; e) de caráter documental, por trazer marcas históricas. Por isso, os livros didáticos podem ser estudados a partir de variados focos de análises.

Buscando observar quais foram os focos de análises desses artigos que criamos as seguintes categorias: a) "conteúdos", quando preocupados prioritariamente em examinar quais e como os conteúdos estão presentes nos livros; b) "institucionalização", quando preocupados em identificar o status da área das Ciências Sociais ou seu ensino; c) "recursos didático-pedagógicos”, quando voltados a examinar quais recursos didáticos estão presentes nas obras; d) 
"usos", quando a proposta é observar os usos dos livros didáticos por professores ou alunos; e) "sentidos da Sociologia", refere-se à preocupação em saber qual sentido se dá à Sociologia na obra ou parte dela; f) "discussão metodológica", quando se utiliza de uma análise para apontar caminhos metodológicos para a pesquisa manualística; g) "mercado editorial”, quando se utiliza de recursos da manualística para compreender o estágio/estado do mercado editorial brasileiro e; h) "metodologias e teorias", quando a análise recai no propósito de identificar as metodologias presentes e quais teorias as fundamentam. Os dados são apresentados na Tabela 3.

Tabela 3 - Foco de análise dos artigos científicos, que tomam os manuais/ livros didáticos de Sociologia como objeto ou fonte de pesquisa.

\begin{tabular}{c|c|c|c|c}
\hline Foco & a) Conteúdos & b) Institucionalizaçáo & $\begin{array}{c}\text { c) Recursos } \\
\text { didático-pedagógicos }\end{array}$ & d) Usos \\
\hline Número & 35 & 5 & 5 & 2 \\
\hline Percentual & 67,2 & 9,6 & 9,6 & 3,8 \\
\hline Foco & $\begin{array}{c}\text { e) Sentido da } \\
\text { Sociologia }\end{array}$ & $\begin{array}{c}\text { f) Discussáo } \\
\text { metodológica }\end{array}$ & g) Mercado editorial & $\begin{array}{c}\text { h) Metodologias } \\
\text { e teorias }\end{array}$ \\
\hline Número & 2 & 1 & 1 & 1 \\
\hline Percentual & 3,8 & 1,9 & 1,9 & 1,9 \\
\hline
\end{tabular}

Fonte: Elaboração própria, com base em levantamento realizado no Google Scholar, em 30 dez. 2020.

Observando o conjunto dos artigos notamos que a maior parte deles se voltam a analisar os conteúdos presentes nos manuais. Os demais focos de análise aparecem com reduzida participação nesse conjunto. Ao todo, foram 35 artigos que se voltaram a analisar conteúdos (alguns realizando análises de discurso). Nas análises de conteúdo e de discurso encontramos os "temas em destaque". Tais temas em destaque são apresentados na Tabela 4. 
Tabela 4 - Temas em destaque analisados nos artigos científicos, que tomam os manuais/livros didáticos de Sociologia como objeto ou fonte de pesquisa e cujo foco foram a análise de conteúdo ou de discurso.

\begin{tabular}{ccccccccc}
\hline Tema & Gênero & $\begin{array}{c}\text { Sociologia } \\
\text { Católica }\end{array}$ & $\begin{array}{c}\text { Temática } \\
\text { étnico-racial }\end{array}$ & Antropologia & $\begin{array}{c}\text { Ciência } \\
\text { Política }\end{array}$ & Estado & Religiáo de matriz africana \\
\hline No & $7^{*}$ & 4 & 3 & 2 & 2 & 2 & 1 \\
\hline Tema & $\begin{array}{c}\text { Clássicos da } \\
\text { Sociologia }\end{array}$ & $\begin{array}{c}\text { Refúgio/ } \\
\text { refugiado }\end{array}$ & $\begin{array}{c}\text { Direitos } \\
\text { Humanos }\end{array}$ & $\begin{array}{c}\text { Movimentos } \\
\text { sociais }\end{array}$ & $\begin{array}{c}\text { Classes } \\
\text { sociais }\end{array}$ & $\begin{array}{c}\text { Senso } \\
\text { comum }\end{array}$ & Família & Cidadania \\
\hline No & 1 & 1 & 1 & 1 & 1 & 1 & 1 & 1 \\
\hline
\end{tabular}

Nota: *Os temas étnico-racial e feminismo aparecem uma vez cada, juntamente ao tema gênero, que é foco do artigo.

Fonte: Elaboração própria, com base em levantamento realizado no Google Scholar, em 30 dez. 2020.

Por meio da Tabela 4 observamos que o tema gênero foi objeto de atenção de 7 artigos, que se dedicaram a analisar os livros didáticos de Sociologia e a temática étnico-racial de 3 produçóes, o que nos parece ser reflexo de açóes coletivas (que alcançaram importantes conquistas no campo do currículo e no campo legislativo), que visam a equidade entre gênero e raça; embora outros temas demandados por movimentos sociais tivessem sido objetos de análises de apenas 1 artigo, ou nenhum. A Sociologia católica foi a preocupação de 4 artigos. Ao todo encontramos 15 temas em destaque, envolvendo 29 artigos, o que representa 55,7\% do volume total. Já Engerroff (2017) identificou que $23,3 \%$ das teses e dissertaçóes voltavam-se para os temas em destaque; dados que apontam para a hipótese de que o tipo de pesquisa impacta nas escolhas dos problemas de investigação dos autores e autoras.

Tabela 5 - Principais métodos adotados pelos artigos científicos, que tomam os manuais/livros didáticos de Sociologia como objeto ou fonte de pesquisa.

\begin{tabular}{c|c|c|c|c|c|c|c|c|c}
\hline Tipo & $\begin{array}{c}\text { Análise } \\
\text { de } \\
\text { conteúdo }\end{array}$ & $\begin{array}{c}\text { Análise } \\
\text { do } \\
\text { discurso }\end{array}$ & $\begin{array}{c}\text { Análise de } \\
\text { conteúdo e } \\
\text { trajetórias }\end{array}$ & $\begin{array}{c}\text { Revisáo } \\
\text { bibliográfica }\end{array}$ & $\begin{array}{c}\text { Discussáo } \\
\text { metodológica }\end{array}$ & Entrevista & Observaçáo & $\begin{array}{c}\text { Entrevista } \\
\text { e } \\
\text { observaçáo }\end{array}$ & Total \\
\hline Número & 38 & 7 & 1 & 2 & 1 & 1 & 1 & 1 & 52 \\
\hline Percentual & 73 & 13,4 & 1,9 & 3,8 & 1,9 & 1,9 & 1,9 & 1,9 & 100 \\
\hline
\end{tabular}

Fonte: Elaboração própria, com base em levantamento realizado no Google Scholar, em 30 dez. 2020. 
Buscamos observar os métodos adotados pelos 52 artigos. As pesquisas adotaram, prioritariamente ${ }^{4}$, a análise de conteúdo e a análise do discurso. Contudo, nos chamou atençáo a marginalidade dos procedimentos metodológicos no interior dos artigos. Considerando obras referenciais em análise de conteúdo, notamos que Bardin (2002), por exemplo, é citado em apenas 4 dos 38 artigos que se propuseram a utilizar tal metodologia. Nenhuma outra obra que tenha em seu título "análise de conteúdo" aparece nas 1.154 referências (dissertaçôes, teses, artigos, capítulos de livros, livros e pesquisas de órgãos públicos e privados) mobilizadas pelos 52 artigos. Quanto às referências às obras voltadas à análise do discurso, vamos encontrar um pequeno volume. A Tabela 6 apresenta esses dados.

Tabela 6 - Referências sobre a análise do discurso presente nas referências dos artigos científicos, que tomam os manuais/livros didáticos de Sociologia como objeto ou fonte de pesquisa.

\begin{tabular}{cl}
\hline No & \multicolumn{1}{c}{ Obra } \\
\hline 2 & $\begin{array}{l}\text { BERNSTEIN, Basil. A Estruturação do discurso pedagógico: classes, códigos e controle. } \\
\text { Petrópolis: Vozes, 1996. }\end{array}$ \\
\hline 2 & $\begin{array}{l}\text { ORLANDI, Eni Pulcinelli. As formas do silêncio: no movimento dos sentidos. } 4 \text { ed. Campinas, } \\
\text { SP: Editora da Unicamp, 1997. }\end{array}$ \\
\hline 1 & CHARAUDEAU, P. Linguagem e discurso: modos de organização. São Paulo: Contexto, 2016. \\
\hline 1 & $\begin{array}{l}\text { CHARTIER, A., \& HÉBRARD, J. (1995). Discursos sobre a leitura: 1880-1980. São Paulo, } \\
\text { SP: Ática. }\end{array}$ \\
\hline 1 & $\begin{array}{l}\text { FOUCAULT, Michel. A Ordem do Discurso: aula inaugural no Collège de France pronunciada } \\
\text { em 2 de dezembro de 1970. 24.ed. São Paulo: Ediçóes Loyola, 2014. }\end{array}$ \\
\hline 1 & $\begin{array}{l}\text { MAINGUENEAU, Dominique. Novas tendências em análise do discurso. 3a ed. Campinas - } \\
\text { São Paulo: Editora da Universidade Estadual de Campinas, 1997. }\end{array}$ \\
\hline 1 & $\begin{array}{l}\text { MARTINS, Isabel. Analisando livros didáticos na perspectiva dos estudos do discurso: com- } \\
\text { partilhando reflexôes e sugerindo uma agenda para a pesquisa. Proposiçôes, v.17, n. I (49), } \\
\text { p.117-136, 2006. }\end{array}$ \\
\hline 1 & $\begin{array}{l}\text { ORLANDI, Eni Pulcinelli. A linguagem e seu funcionamento: as formas do discurso. Campinas: } \\
\text { Pontes, 2009. }\end{array}$ \\
\hline 1 & $\begin{array}{l}\text { PÊCHEUX, Michel. O discurso: estrutura ou acontecimento. 4. ed. Campinas, SP: Pontes } \\
\text { Editores, 2006. }\end{array}$ \\
\hline 1 & $\begin{array}{l}\text { PÊCHEUX, Michel. Semântica e discurso: uma crítica à afirmação do óbvio. 2. ed. Campinas, } \\
\text { SP: Editora da UNICAMP, 1995. }\end{array}$ \\
\hline
\end{tabular}

Fonte: Elaboração própria, com base em levantamento realizado no Google Scholar, em 30 dez. 2020.

4 Consideramos apenas o método predominantemente adotado em cada artigo, ainda que marginalmente tenham sido mobilizados outros. 
Examinando as referências dos 52 artigos observamos uma preocupação secundária com as discussóes (e apresentaçóes) metodológicas, sobretudo no que se refere às fundamentaçóes teóricas para tais discussóes. Também observamos que as referências que se enquadram no campo da manualística são pouco mobilizadas no conjunto dos artigos examinados.

Destacamos que análises mais aprofundadas e com recortes de análises focadas nas metodologias ou nas bases teóricas desses artigos carecem de estudos futuros. Aqui, a preocupação central é apresentar um panorama da produção científica, proposta típica das pesquisas denominadas estados da arte; o que corrobora para a compreensão das configuraçóes do subcampo de pesquisa do ensino de Sociologia.

Passamos a observar as principais referências bibliográficas que embasam os 52 artigos encontrados, dados que apresentamos por meio da Tabela 7. Tal observação visa identificar se existem "referências" consolidadas, ainda que, no Brasil, a manualística voltada aos livros didáticos de Sociologia seja recente, como já demonstrado por meio do Gráfico 1 .

Tabela 7 - Trabalhos que foram referências em cinco ou mais artigos científicos, que tomam os manuais/livros didáticos de Sociologia como objeto ou fonte de pesquisa.

\begin{tabular}{|c|c|c|c|}
\hline N. & Título & Autoria / ano & Tipo \\
\hline 15 & $\begin{array}{l}\text { A institucionalização da Sociologia no Brasil: os } \\
\text { primeiros manuais e cursos. }\end{array}$ & MEUCCI, Simone (2000) & Dissertação \\
\hline 11 & $\begin{array}{l}\text { Notas sobre o pensamento social brasileiro nos } \\
\text { livros didáticos de Sociologia. }\end{array}$ & MEUCCI, Simone (2014) & Artigo \\
\hline 8 & $\begin{array}{l}\text { Sobre a rotinização da Sociologia no Brasil: os } \\
\text { primeiros manuais didáticos, seus autores, suas } \\
\text { expectativas. }\end{array}$ & MEUCCI, Simone (2007) & Artigo \\
\hline 7 & $\begin{array}{l}\text { Institucionalização da Sociologia no Brasil: pri- } \\
\text { meiros manuais e cursos. }\end{array}$ & MEUCCI, Simone (2011) & Livro \\
\hline 7 & $\begin{array}{l}\text { A Sociologia volta à escola: Um estudo dos } \\
\text { manuais de Sociologia para o ensino médio no } \\
\text { Brasil. }\end{array}$ & $\begin{array}{l}\text { SARANDY, Flávio Marcos } \\
\text { Silva (2004) }\end{array}$ & Dissertaçáo \\
\hline 6 & $\begin{array}{l}\text { O mercado do livro didático no Brasil: da cria- } \\
\text { ção do Programa Nacional do Livro Didático } \\
\text { (PNLD) à entrada do capital internacional } \\
\text { espanhol (1985-2007). }\end{array}$ & $\begin{array}{l}\text { CASSIANO, Célia Cristina } \\
\text { de Figueiredo (2007) }\end{array}$ & Tese \\
\hline 6 & História das ideias pedagógicas. & SAVIANI, Dermeval (2007) & Livro \\
\hline
\end{tabular}




\begin{tabular}{clll}
\hline N. & \multicolumn{1}{c}{ Título } & \multicolumn{1}{c}{ Autoria / ano } & \multicolumn{1}{c}{ Tipo } \\
\hline 6 & $\begin{array}{l}\text { O ensino das Ciências Sociais/Sociologia no } \\
\text { Brasil: histórico e perspectivas. }\end{array}$ & $\begin{array}{l}\text { SILVA, Ileize Luciana } \\
\text { Fiorelli (2010) }\end{array}$ & Cap. De livro \\
\hline 5 & $\begin{array}{l}\text { A Sociologia educacional no Brasil (1946- } \\
\text { 1971): análise sobre uma instituição de ensino } \\
\text { católica. }\end{array}$ & $\begin{array}{l}\text { CIGALES, Marcelo Pinheiro } \\
(2014)\end{array}$ & Dissertação \\
\hline 5 & O livro didático em questáo. & $\begin{array}{l}\text { FREITAG, Barbara; MOTTA, } \\
\text { Valéria R; COSTA, Wanderley F. } \\
\text { da.(1989) }\end{array}$ & Livro \\
\hline & $\begin{array}{l}\text { A Sociologia no Ensino Médio: desafios insti- } \\
\text { tucionais e epistemológicos para a consolidação } \\
\text { da disciplina. }\end{array}$ & $\begin{array}{l}\text { SILVA, Ileize Luciana } \\
\text { Fiorelli (2007) }\end{array}$ & Artigo \\
\hline 5 & $\begin{array}{l}\text { Revisitando a história do ensino de Sociologia na } \\
\text { Educaçáo Básica. }\end{array}$ & OLIVEIRA, Amurabi (2013) & Artigo \\
\hline
\end{tabular}

Fonte: Elaboração própria, com base em levantamento realizado no Google Scholar, em 30 dez. 2020.

Observamos que as referências mais recorrentes nos 52 trabalhos foram publicadas até o ano de 2014. Os trabalhos mais citados foram a dissertação de mestrado $\left(2000,2011^{5}\right)$ de Meucci e dois de seus artigos (2007, 2014), que são desdobramentos de sua dissertação. A qualidade, o ineditismo e o pioneirismo (em examinar obras da primeira metade do século XX) ${ }^{6}$ das três produçôes de Meucci, assim como sua presença em outros espaços relacionados ao ensino de Sociologia, explica, em alguma medida, a recepção desses trabalhos. Se Meucci apresentou ineditismo ao examinar manuais de Sociologia da primeira metade do século XX, Flávio Marcos Silva Sarandy (2004) inaugurou as análises de livros didáticos de Sociologia do início do século XXI, tornando sua dissertação de mestrado amplamente conhecida no interior do subcampo de pesquisa do ensino de Sociologia. A hipótese levantada por Goulart e Sousa (2019) de que Basil Bernstein (por sua contribuição ao tema da recontextualização) seria uma referência importante para os estudos do livro didático de Sociologia, não se confirma no conjunto dos artigos publicados sobre o tema. Bernstein é citado por apenas 2, dos 52 artigos em análise.

A despeito de predominar pesquisas que se voltaram aos livros didáticos contemplados no PNLD, as referências mais citadas tratam de manuais da pri-

\footnotetext{
5 Versão de sua dissertação em forma de livro, lançada pela editora Hucitec.

6 Antes de Meucci, em 1996, Machado já examinava, em dissertação de mestrado, 4 livros didáticos de Sociologia, editados entre os anos de 1985 e 1994. Contudo, tal trabalho não teve a mesma repercussão dos trabalhos de Meucci $(2000,2011,2014)$.
} 
meira metade do século XX. Isso pode ser explicado, em parte, por dois aspectos: a) pela escassez de pesquisas com esse recorte, o que faz com que não haja um espraiamento de referências quando o referido período é abordado; e b) a recorrente presença de um breve retrospecto da história do ensino da Sociologia no Brasil. Importa destacar que a maior frequência de uma obra ou autor no conjunto das referências não significa, necessariamente, que a obra (ou o autor) é mobilizada como principal embasamento teórico ou analítico.

Ao todo, os 52 artigos trazem 1.292 referências, sendo dessas 133 normativas federais (Brasil), 2 estaduais (Santa Catarina) e 3 normativas estrangeiras (espanholas). A existência de programa nacional voltado ao livro didático, de Lei federal que tornava, até 2017, obrigatório o ensino de Sociologia e de diretrizes nacionais que impactaram positiva e negativamente na presença da disciplina no currículo, explicam, em grande parte, o maior volume de citaçóes de normativas federais. Nota-se que, dentre as 1.154 referências (as dissertaçóes, teses, artigos, capítulos de livros, livros e pesquisas de órgãos públicos e privados), identificamos poucos trabalhos citados por mais de 4 artigos que compóem o corpus de nossa análise. Isso evidencia uma fraca rede entre esses trabalhos, pesquisadores e pesquisadoras. Dos 52 artigos, apenas 7 deles aparecem nas referências de 5 ou mais artigos. Esses dados revelam aspectos de um subcampo ainda em processo de consolidação, este carecendo, em grande medida, de outros subcampos de pesquisa para fundamentar os artigos publicados.

Sabemos que uma possível rede se forma a partir de autores, quando esses mantêm diálogos entre si. No caso de análise bibliométrica, uma rede se materializa quando um conjunto de trabalhos se referenciam de forma mútua, tecendo uma rede de referências interligadas. Por isso, buscamos examinar os autores mais citados nos 52 artigos $^{7}$. Os dados coletados e organizados sáo apresentados na Tabela 8 .

\footnotetext{
7 Não é a proposta aqui realizar um estudo de redes, algo que julgamos importante, mas que demanda outra metodologia e um espaço maior.
} 
Tabela 8 - Autores que tiveram cinco (05) ou mais trabalhos referenciados nos artigos científicos, que tomam os manuais/livros didáticos de Sociologia como objeto ou fonte de pesquisa.

\begin{tabular}{ccl}
\hline $\begin{array}{c}\text { No de trabalhos } \\
\text { referenciados }\end{array}$ & $\begin{array}{c}\text { No total de } \\
\text { citaçóes recebidas }\end{array}$ & \multicolumn{1}{c}{ Autores } \\
\hline 17 & 23 & OLIVEIRA, Amurabi \\
\hline 15 & 22 & BOURDIEU, Pierre \\
\hline 14 & 56 & MEUCCI, Simone \\
\hline 10 & 15 & CIGALES, Marcelo Pinheiro. \\
\hline 9 & 11 & BODART, Cristiano das Neves \\
\hline 8 & 8 & AZEVEDO, Fernando de*. \\
\hline 6 & 10 & MORAES, Amaury César \\
\hline 6 & 7 & MARX, Karl \\
\hline 6 & 6 & CARVALHO, Marta Maria Chagas de. \\
\hline 5 & 11 & MICELI, Sérgio \\
\hline 5 & 6 & FERNANDES, Florestan. \\
\hline 5 & 6 & HANDFAS, Anita \\
\hline
\end{tabular}

Nota: *Não foram consideradas as citaçôes a obras didáticas/manuais.

Fonte: Elaboraçâo própria, com base em levantamento realizado no Google Scholar, em 30 dez. 2020.

Observando a Tabela 8 notamos que dentre os autores e autoras com maior número de trabalhos referenciados no corpus de nossa análise, 5 possuem publicações que analisam livros didáticos de Sociologia, sendo eles, por ordem de maior volume, Amurabi de Oliveira (17), Simone Meucci (14), Marcelo Pinheiro Cigales (10), Cristiano das Neves Bodart (9) e Marta Maria C. de Carvalho (6). Esses dados reforçam a hipótese ${ }^{8}$ de que não há uma rede bem constituída ou consolidada entre os pesquisadores e as pesquisadoras que se dedicam, em alguma medida, ao tema em questão.

\footnotetext{
8 Para comprovar tal hipótese é necessário um estudo de redes que envolva autores/as e artigos, o que não nos propomos a fazer neste artigo.
} 


\section{O perfil dos autores}

Passamos, nesta seção, a examinar aspectos constituintes do perfil dos autores e das autoras dos 52 artigos, o que fazemos considerando o ano de publicação de seus textos. Observando a autoria, notamos que 19 artigos (36,5\%) foram produzidos em coautoria; sendo que 18 possuem dois autores ou autoras e 1 artigo tem 5 autores ou autoras. Na pesquisa de Bodart e Tavares (2020), envolvendo os artigos sobre o ensino de Sociologia, constatou-se que a coautoria aparece em 41,5\% dos artigos publicados em periódicos de estrato superior nas áreas de Sociologia, Educação e Ensino. Parece ser uma regularidade do subcampo de pesquisa do ensino de Sociologia, a tendência de artigos assinados por apenas um pesquisador ou pesquisadora.

Ao todo, os 52 artigos envolveram 58 autores e autoras, sendo $40 \%$ do sexo masculino e $60 \%$ do sexo feminino. A maior participação de mulheres também foi apontada no estado da arte das teses e dissertaçóes sobre o ensino de Sociologia (BODART; CIGALES, 2017), das teses e dissertaçóes sobre livro didático de Sociologia (ENGERROFF, 2017), dos dossiês sobre ensino de Sociologia (BRUNETTA; CIGALES, 2018), dos artigos sobre o ensino de Sociologia publicados em periódicos de estratos superiores (BODART; TAVARES, 2020), dos artigos sobre a história do ensino de Sociologia (ENGERROFF; CIGALES; THOLL, 2017), assim como dos artigos apresentados no GT "O livro didático de Ciências Sociais: avanços e desafios”, do V ENESEB, em 2017 (GOULART; SOUSA, 2019). Todas essas pesquisas apontam para uma maior participação autoral de mulheres no subcampo do ensino de Sociologia.

A tabela 9 apresenta os autores e as autoras dos 52 textos, destacando aqueles ou aquelas que mais participam com artigos no corpus desta pesquisa.

Tabela 9 - Autores* dos artigos científicos, que tomam os manuais/ livros didáticos de Sociologia como objeto ou fonte de pesquisa.

\begin{tabular}{lcc}
\multicolumn{1}{c}{ Autor/a } & No de artigos & Vínculo institucional** $^{*}$ \\
\hline Marcelo Pinheiro Cigales & 5 & UFSC \\
\hline Amurabi de Oliveira & 4 & UFSC \\
\hline Simone Meucci & 4 & UFPR \\
\hline Ana Martina Baron Engerroff & 3 & UFSC \\
\hline Cristiano das Neves Bodart & 2 & UFAL \\
\hline Guilherme Fernando Schnekenberg & 2 & SEE-MG \\
\hline
\end{tabular}




\begin{tabular}{|c|c|c|}
\hline Autor/a & No de artigos & Vínculo institucional ${ }^{* *}$ \\
\hline Renato Kendy Hidaka & 2 & \\
\hline Silvia Helena Andrade de Brito & 2 & UFMS \\
\hline \multicolumn{3}{|c|}{ Demais autores com 1 artigo publicado: } \\
\hline \multicolumn{3}{|c|}{$\begin{array}{l}\text { Alessa Coelho Lauriano (UFPR); Ana Carolina Araújo de França (UFRJ); Anderson Felipe dos anjos } \\
\text { Duarte (Fundaj); André Rocha Santos (IFSP); Angélica Gomes da Silva Gouvêa (n/e); Anicélia Ferreira } \\
\text { da Silva (Fundaj); Bárbara de Souza Fontes (CP II); Beatrice Cavalcante Limoeiro (CP II); Beatriz de } \\
\text { Melo Silva (UEL); Caroline Souza Castro (CP II); David Gonçalves Soares (UFRJ); Décio Gatti Júnior } \\
\text { (UFU); Diane Macedo (UFSC); Diego Pontes (UFPR); Elaine Aparecida Teixeira Pereira (UFSC); } \\
\text { Elizandra Cristina Rodrigues da Silva (UFAL); Ellen Fernanda Araújo (UFRJ); Erinaldo Ferreira Carmo } \\
\text { (CA- UFPE); Ewerton Diego de Souza (UFAL); Fernanda Di Flora (UEL); Gabriela Sebba Abdo (IFSP); } \\
\text { Gabriella Romagnoli Chagas (UEL); Heloisa C. Domingos (UFSC); Jefferson Evanio da Silva (Fundaj); } \\
\text { Joanildo Albuquerque Burity (Fundaj); Jose Jairo Vieira (UFRJ); Julia Polessa Maçaira (UFRJ); Kênia } \\
\text { Mara Gaedtke (UFSC); Kira Mahamud Ângulo (FED-Espanha); Laís Celis Merissi (UFPR); Luiz Felipe } \\
\text { Guimarães Bom (CP II); Marcela de Oliveira Nunes (UEM); Marcelo Sales Galdino (SEDUC-PE); } \\
\text { Marcia Menezes Thomaz Pereira (UERJ); Maria Aparecida Bridi (UFPR); Maria Auxiliadora Cavazotti } \\
\text { (UFPR); Maria das Dores Daros (UFSC); Mariane da Silva Pisani (UFSC); Natan Schmitz Kremer } \\
\text { (UFSC); Patrícia dos Santos Dotti do Prado (UFPR); Rachel Tomás dos Santos Abrão (UFSC); Ricardo } \\
\text { Cortez Lopes (IBCMED); Ricardo Pereira da Silva (UFSCAR); Rodrigo Moreira Vieira (IFPA); Sandra } \\
\text { Maria de Oliveira (PMU-MG); Silas Cassio Gomes Nascimento (UFPE); Tamara Vieira (SEED/PR); } \\
\text { Thayene Gomes Cavalcante (SSE-PB); Valci Melo Silva dos Santos (UFAL) e Vinícius Carvalho Lima } \\
\text { (IFRJ). }\end{array}$} \\
\hline
\end{tabular}

Nota: *Foi considerado coautoria. ${ }^{* *} \mathrm{Na}$ data de publicação do artigo. Para os vínculos institucionais não encontrados usamos "n/e".

Fonte: Elaboraçẫo própria, com base em levantamento realizado no Google Scholar, em 30 dez. 2020.

Os 4 autores/as que mais publicaram artigos que analisam livros didáticos (ou manuais) de Sociologia estavam, na data da coleta dos dados, vinculados às universidades localizadas no Sul do Brasil, sendo dois docentes e dois discentes de pós-graduação stricto sensu. Os autores e autoras que mais publicaram artigos foram, respectivamente: Cigales (5 artigos), que na época desenvolvia pesquisa de pós-graduação stricto sensu sobre manuais de Sociologia; Oliveira (4 artigos), docente (UFSC), pesquisador do ensino de Sociologia e orientador de doutoramento de Cigales (UFSC); Meucci (4 artigos), docente (UFPR) e pesquisadora do ensino de Sociologia, cujos artigos são desdobramento de sua dissertação de mestrado e; Engerroff ( 3 artigos), mestranda, cujo tema de seu Trabalho de Conclusão de Curso (TCC) da graduação em Ciências Sociais e de sua dissertação se voltam aos livros didáticos; ambos trabalhos orientados por Oliveira, na Universidade Federal de Santa Catarina (UFSC).

Nos motivamos pela hipótese de que a identidade em comum dos pesquisadores seja a formação inicial (a graduação), buscamos observar qual é a 
graduação dos(as) autores. Assim, observamos que 80\% dos autores e coautores, ou estavam cursando, ou eram formados em Ciências Sociais, ou em Sociologia? Quando consideramos apenas o(a) primeiro(a) autor(a), esse percentual é um pouco maior, $87 \%$. No recorte de Bodart e Tavares (2020), o percentual de graduados em Ciências Sociais foi de 73,8\%; no recorte de Brunetta e Cigales (2018), 88\%. No GT “O livro didático de Ciências Sociais: avanços e desafios”, proposto no V ENESEB (2017), quase a totalidade dos autores eram graduados em Ciências Sociais (GOULART; SOUSA, 2019). Esses dados nos levam a concluir que o volume maior de autores oriundos das Ciências Sociais não é exclusiva de um recorte do subcampo do ensino de Sociologia voltado aos livros didáticos, mas de todo o subcampo de pesquisa do ensino de Sociologia. Os dados que coletamos e sistematizamos são apresentados de forma detalhada nos Gráficos 4 e 5.

Gráfico 4 - Perfil de formação inicial de todos dos autores e autoras de artigos científicos, que tomam os manuais/livros didáticos de Sociologia como objeto ou fonte de pesquisa.

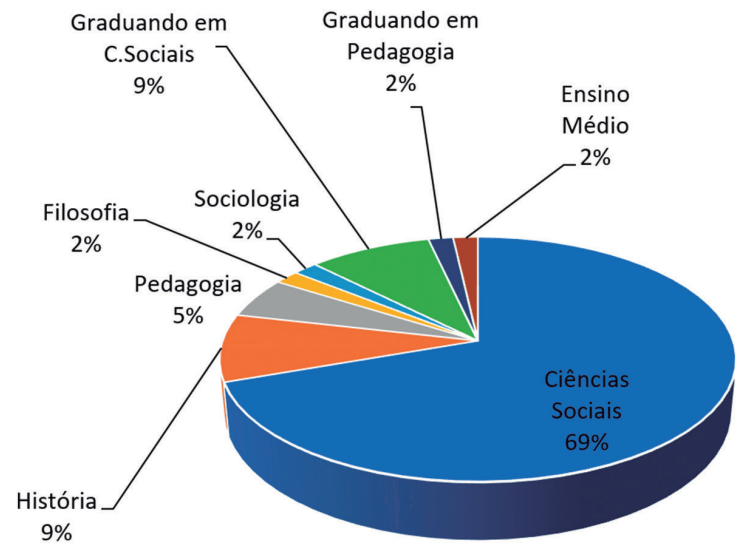

Fonte: Elaboração própria, com base em levantamento realizado no Google Scholar, em 30 dez. 2020.

\footnotetext{
9 Não foi possível observar o grau (licenciatura ou bacharelado) por falta de informações nos currículos lattes dos autores e das autoras.
} 
Gráfico 5 - Perfil de formação inicial dos primeiros autores e autoras de artigos científicos, que tomam os manuais/livros didáticos de Sociologia como objeto ou fonte de pesquisa.

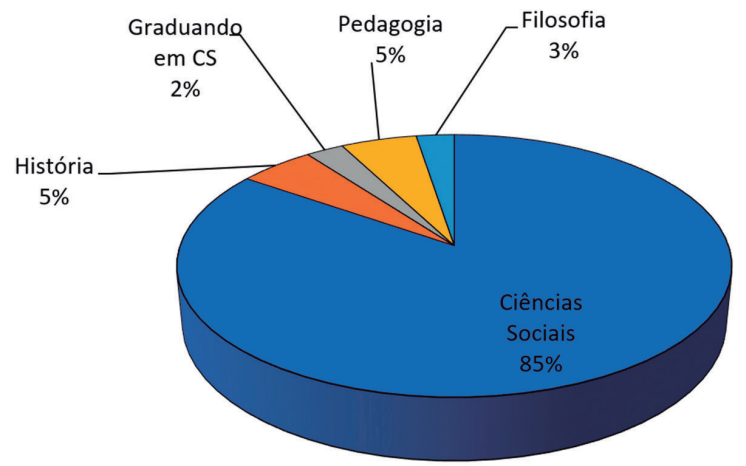

Fonte: Elaboração própria, com base em levantamento realizado no Google Scholar, em 30 dez. 2020.

Os dados apresentados nos gráficos 4 e 5 corroboram para concluirmos que as pesquisas sobre livros didáticos de Sociologia são produzidas por autores e autoras oriundos das Ciências Sociais. Buscamos examinar a titulação dos autores e coautores; dados que apresentamos nas tabelas 10 e 11 .

Tabela 10 - Perfil dos autores e coautores que publicaram artigos científicos, que tomam os manuais/livros didáticos de Sociologia como objeto ou fonte de pesquisa.

\begin{tabular}{c|c|c|c|c|c|c|c}
\hline $\begin{array}{c}\text { Escolaridade/ } \\
\text { titulaçáo }\end{array}$ & Doutor & Doutorando & Mestre & Mestrando & Graduado & Graduando & $\begin{array}{c}\text { Ensino } \\
\text { médio }\end{array}$ \\
\hline Número & 21 & 7 & 14 & 4 & 5 & 6 & 1 \\
\hline Percentual & $36 \%$ & $12 \%$ & $24 \%$ & $7 \%$ & $8 \%$ & $10 \%$ & $2 \%$ \\
\hline
\end{tabular}

Fonte: Elaboração própria, com base em levantamento realizado no Google Scholar, em 30 dez. 2020.

Tabela 11 - Perfil dos autores (10 autor) que publicaram artigos científicos, que tomam os manuais/livros didáticos de Sociologia como objeto ou fonte de pesquisa.

\begin{tabular}{c|c|c|c|c|c}
\hline $\begin{array}{c}\text { Escolaridade/ } \\
\text { titulaçáo }\end{array}$ & Doutor & Doutorando & Mestre & Mestrando & Graduado \\
\hline Número & 15 & 7 & 12 & 3 & 4 \\
\hline Percentual & $37 \%$ & $17 \%$ & $29 \%$ & $7 \%$ & $5 \%$ \\
\hline
\end{tabular}

Fonte: Elaboração própria, com base em levantamento realizado no Google Scholar, em 30 dez. 2020. 
Considerando autores e coautores, notamos que $72 \%$ possuíam titulação de mestre ou doutor. Examinando apenas os primeiros autores, esse percentual sobe para $83 \%$. De forma específica, observamos que as pesquisas são produzidas, em sua maioria, por doutores. Dentre os autores que publicaram artigos em dossiês sobre o ensino de Sociologia, Brunetta e Cigales (2018) identificaram que $88,8 \%$ eram doutores ou mestres, dados próximos das nossas constataçóes. Em levantamento com o mesmo recorte de Brunetta e Cigales (2018), Bodart e Souza (2017) observaram um percentual de $84,7 \%$. Já dentre os autores de artigos sobre a história do ensino de Sociologia, esse percentual foi de 83,8\% (ENGERROFF; CIGALES; THOLL, 2017). A fim de examinar a área de origem das titulaçóes, recorremos ao currículo lattes dos autores e autoras para coletar essa informação. Os dados são apresentados na Tabela 12.

Tabela 12 - Perfil dos autores portadores de títulos de pós-graduação stricto senso que publicaram artigos científicos, que tomam os manuais/

livros didáticos de Sociologia como objeto ou fonte de pesquisa.

\begin{tabular}{l|c|c|c|c|c}
\hline \multicolumn{1}{c|}{ Área } & Doutores & Doutorandos & Mestrandos & Mestres & Total \\
\hline Sociologia* & 10 & 3 & 3 & 2 & $\mathbf{1 8}$ \\
Educaçáo & 6 & 1 & 0 & 4 & $\mathbf{1 1}$ \\
Ciência Política & 2 & 0 & 0 & 0 & $\mathbf{2}$ \\
Ciências Sociais & 1 & 2 & 1 & 6 & $\mathbf{1 0}$ \\
Antropologia & 1 & 1 & 0 & 0 & $\mathbf{2}$ \\
Outros & 0 & 0 & 0 & 2 & $\mathbf{2}$ \\
\hline Total & $\mathbf{2 0}$ & 7 & $\mathbf{4}$ & $\mathbf{1 4}$ & $\mathbf{4 5}$
\end{tabular}

Nota: *Cursos de Sociologia e de Sociologia Política.

Fonte: Elaboraçâo própria, com base em levantamento realizado no Google Scholar, em 30 dez. 2020.

Em recorte maior, examinando para as teses e dissertações sobre o ensino de Sociologia, Bodart e Cigales (2017) notaram um certo equilíbrio entre as áreas de Ciências Sociais e Educação. Observando as titulações dos autores e autoras dos artigos que aqui examinamos, notamos uma predominância de titulados em programas das áreas das Ciências Sociais $(71,1 \%)$ sobre titulados em programas de Educaçáo (24,4\%). Dentre os doutores e mestres autores de artigos publicados em dossiês sobre o ensino de Sociologia, Brunetta e Cigales (2018) identificaram percentuais muito próximos. Engerroff (2017), em sua pesquisa sobre as teses e dissertações sobre livros didáticos de Sociologia, notou que $63,3 \%$ dos trabalhos que foram defendidos em programas de pós-gradu- 
ação stricto sensu eram em Ciências Sociais; já nos programas de Educação, o percentual foi de $36,7 \%$. Esses dados revelam que, a despeito da importante participação de titulados em Educação, a participação de mestres e doutores nas Ciências Sociais é maior. Contudo, podemos inferir a partir dos dados encontrados por esta pesquisa, assim como as demais pesquisas de estado da arte já publicadas, que o subcampo de pesquisa do ensino de Sociologia está vinculado aos campos da Educação e da Sociologia. A identidade profissional que aproxima os pesquisadores não é o doutorado, mas a formação inicial: Ciências Sociais. Nesse sentido, compreender o subcampo de pesquisa do ensino de Sociologia demanda reconhecer a importância da formação inicial dos agentes sociais na constituição de uma "comunidade acadêmica" que se mobiliza em torno desse tema.

Em 2011, Handfas afirmava que "ainda [eram] poucas as pesquisas que buscam pensar sociologicamente o ensino de Sociologia” (HANDFAS, 2011, p. 398). Tal afirmativa deu-se frente à constatação de que a maior parte das teses e dissertaçóes defendidas até aquele momento eram oriundas de programas de pós-graduação em Educação. Passados dez anos da pesquisa de Handfas (2011), constatamos em nosso recorte que há, dentre os que vêm se debruçando sobre os livros didáticos (ou manuais) de Sociologia, um volume maior de pesquisadores pós-graduados da área da Sociologia.

Outro aspecto importante para compreender um campo ou um subcampo está em identificar as instituiçóes presentes em seu interior. Por isso, buscamos observar o vínculo institucional dos autores na época em que seus artigos foram publicados. Os dados são apresentados na Tabela 13.

Tabela 13 - Vínculo institucional dos autores que publicaram artigos científicos, que tomam os manuais/livros didáticos de Sociologia como objeto ou fonte de pesquisa.

\begin{tabular}{lcl|lcl}
\hline \multicolumn{1}{c}{ Instituiçáo } & No de autores & \multicolumn{1}{c|}{ Região } & \multicolumn{1}{c}{ Instituiçáo } & No de autores & Regiáo \\
\hline UFSC & 11 & Sul & IFRJ & 1 & Sudeste \\
UFPR & 7 & Sul & PMU-MG & 1 & Sudeste \\
CP II & 5 & Sudeste & SEDUC-PE & 1 & Nordeste \\
UFRJ & 5 & Sudeste & SEE-MG & 1 & Sudeste \\
FUNDAJ & 4 & Nordeste & SEED-PR & 1 & Sul \\
UFAL & 4 & Nordeste & SSE-PB & 1 & Nordeste \\
IFSP & 3 & Sudeste & UEM & 1 & Sul \\
UEL & 3 & Sul & UERJ & 1 & Sudeste
\end{tabular}




\begin{tabular}{lcl|lcl}
\multicolumn{1}{c}{ Instituiçáo } & No de autores & Regiáo & Instituiçáa & No de autores & \multicolumn{1}{c}{ Regiáo } \\
\hline CA- UFPE & 1 & Nordeste & UFMS & 1 & Centro-Oeste \\
FED-Espanha & 1 & Exterior & UFPE & 1 & Nordeste \\
IBCMED & 1 & Sudeste & UFSCAR & 1 & Sudeste \\
IFPA & 1 & Norte & UFU & 1 & Sudeste \\
\hline
\end{tabular}

Fonte: Elaboração própria, com base em levantamento realizado no Google Scholar, em 30 dez. 2020.

Universidade Federal de Santa Catarina (UFSC) destacou-se como a instituição mais representada (11 autores), seguida da Universidade Federal do Paraná (7 autores). Há um volume maior de autores vinculados às Instituiçóes de Ensino Superior localizadas no Sudeste (10) e no Nordeste (6). O Sul aparece com 5 instituiçôes, o Norte e o Centro-Oeste com 1 cada. Essa mesma concentração foi constatada por Bodart e Cigales (2017) ao examinar a vinculaçáo institucional dos autores de teses e dissertaçóes sobre o ensino de Sociologia. A produção científica que analisa livros didáticos oriundas da UFSC está relacionada diretamente à atuação do professor Amurabi Oliveira como autor e orientador, o que aponta para o entendimento de que sáo os autores que, em alguma medida, têm conformado o subcampo em análise.

Por fim, buscamos examinar se os autores tiveram, até a data da publicação de seus artigos, experiência na docência no ensino básico, isso por termos por hipótese ser comum pesquisadores se voltarem aos objetos presentes em seus cotidianos ou que marcaram suas biografias. Brunetta e Cigales (2018) observaram que dentre os que assinavam os artigos publicados em dossiês sobre o ensino de Sociologia, 58,7\% apresentavam em seus currículos ter atuado, ou estar atuando, como docente na educação básica. No mesmo recorte, Bodart e Souza (2017) observaram o percentual de $63,1 \%$. No caso dos artigos que se voltam à análise de livros didáticos de Sociologia notamos que 57,8\% dos autores e coautores possuíam experiência como docentes no ensino básico. Dentre os primeiros autores, $67,5 \%$ possuíam tal experiência. Os dados nos possibilitam inferir que existe uma clara correlação entre tema da pesquisa e docência no ensino básico, a qual proporciona o contato direto com o objeto e as experiências proporcionadas por ele, o que pode ser um dos fatores explicativos dessa forte correlação.

O fim dos livros disciplinares no PNLD, inclusive de Sociologia, e a substituição por obras de Ciências Humanas e Sociais Aplicadas (Sociologia, Geografia, Filosofia e História) ${ }^{10}$ em um só título (composto por seis volumes), certamente impactará o "retrato" da pesquisa sobre o livro didático face ao

\footnotetext{
${ }^{10}$ Forma como se organizam as disciplinas de Humanidades na Base Nacional Comum Curricular (BNCC).
} 
ensino de Sociologia. Tal mudança pode vir a fomentar novas pesquisas sobre livros didáticos de Ciências Humanas e Sociais Aplicadas, direcionando o olhar dos pesquisadores para novos problemas, inclusive visando entender o lugar da Sociologia nesse novo arranjo do PNLD.

\section{Considerações finais}

Este artigo apresentou um retrato de parte importante das produções acadêmicas sobre o tema. Ainda que a proposta central tenha sido apresentar o estado da arte, nos arriscamos em indicar algumas hipóteses para as configuraçóes identificadas, bem como responder a algumas questóes suscitadas. Certo de que este esforço não dá conta de toda a produção existente, nem mesmo de explicar tal retrato, mas se mostra profícuo para situar pesquisadores e interessados quanto ao que tem sido produzido no Brasil, bem como apresentar aspectos para a compreensão de como o subcampo de pesquisa do ensino de Sociologia vem se configurando.

Dentre os aspectos que conformam o retrato que apresentamos, destacamos a reduzida presença de artigos que tomam os livros didáticos das Ciências Sociais como objeto de análise ou como artefato histórico. Nota-se que os artigos não se concentram em poucos periódicos, favorecendo sua divulgação. $\mathrm{O}$ que, por outro lado, evidencia a náo recepção recorrente do tema em uma mesma revista. Ainda sobre a recepçáo dos artigos em revistas, podemos inferir que espaços de maior prestígio social - os periódicos de estratos superiores - vêm sendo "ocupado" de forma ainda incipiente.

Os elementos aqui destacados nos permitem apontar algumas hipóteses que precisam ser exploradas em pesquisas futuras - que podem explicar essa configuração, são elas: a) a carência do uso de metodológicas mais profícuas; b) o fato de ser recente o interesse pelo tema; e c) a recente circulação e o consumo de livros didáticos de Sociologia no ensino médio, o que ocorreu apenas no ano de 2012, com a inclusão da Sociologia no PNLD. Se por um lado, os primeiros artigos publicados se voltaram para as análises históricas e a institucionalização da Sociologia, os mais recentes voltam-se para os livros contemplados no PNLD. É justamente após a entrada da Sociologia nesse programa, que ocorreu a expansão do volume de artigos publicados sobre os livros didáticos dessa disciplina. Fato também contemporâneo à expansão dos cursos de licenciatura em Ciências Sociais e à manutenção da oferta da disciplina no ensino médio.

As pesquisas em torno dos livros didáticos de Sociologia adotam, prioritariamente, a análise interna dos livros, destacando-se a análise de conteú- 
dos, seguida do interesse em compreender os seus sentidos. Esta pesquisa, sendo um estado da arte, cumpre o importante papel de proporcionar bases para futuras pesquisas que venham a explorar essa configuração. Contudo, em geral, as pesquisas não se voltam de forma detida aos procedimentos teóricos-metodológicos, constatação que abre caminho para futuras pesquisas, que venham a fazer uma produção da Sociologia em torno dos livros didáticos. Julgamos serem necessárias pesquisas futuras que melhor explorem as bases teóricas e metodológicas que vêm sendo utilizadas nessas pesquisas. Dentre os artigos que fazem análises de conteúdos, o tema "gênero" apareceu mais vezes, seguido da temática "étnico-racial”, o que parece ser reflexo dos movimentos sociais e por serem temáticas relativamente novas nos livros didáticos, tendo despertado o interesse dos pesquisadores.

Quanto ao perfil dos autores, há um número maior de: a) mulheres; b) autores com formação inicial nas Ciências Sociais; c) mestres e doutores em Sociologia; e d) autores com alguma experiência na docência do ensino básico.

Os dados encontrados nos possibilitam inferir que a compreensão das dinâmicas de publicação de artigos sobre livros didáticos de Sociologia passa, necessariamente, pela observação das dinâmicas no currículo do ensino médio, nos programas educacionais e na formação de professores de Sociologia.

Em síntese, podemos afirmar que, embora recente, o avanço quantitativo é considerável, contudo, ainda insuficientemente para formar uma ampla rede de pesquisadores - o que revela um subcampo de pesquisa ainda em processo de consolidação. É certo que uma pesquisa como esta, voltada a apresentar o estado da arte, não dá conta de muitas dimensóes que ainda precisam ser exploradas, sobretudo de caráter qualitativo. Também é adequado afirmar que esta pesquisa apresenta importante contribuiçáo para os que desejam conhecer essa parte do subcampo do ensino de Sociologia, dedicada aos estudos dos manuais escolares; fato que reduz a possibilidade de "andarmos em círculos" quando se trata de análises de livros didáticos de Sociologia.

\section{REFERÊNCIAS}

BARDIN, L. Análise de Conteúdo. Lisboa: Edições 70, 2002.

BATISTA, A. A. G. Um objeto variável e instável: textos, impressos e livros didáticos. In: ABREU, M. (org.). Leitura, história e história da leitura. Campinas; São Paulo: Mercado das Letras, 1999. p. 529-576. 
BODART, C. das N. A construção conceitual e empírica do "subcampo" do ensino de Sociologia. In: BODART, C. das N.; SILVA-SAMPAIO, R. O ensino de Sociologia no Brasil. Maceió: Café com Sociologia, 2019. p. 11-38. v.2.

BODART, C. das N.; CIGALES, M. P. Ensino de Sociologia no Brasil (1993-2015): um Estado da Arte na Pós-Graduação. Revista de Ciências Sociais (UFC), Fortaleza, v. 48, p. 256-281, 2017.

BODART, C. das N.; SOUZA, E. D. de. Configuraçóes do ensino de sociologia como um subcampo de pesquisa: análise dos dossiês publicados em periódicos acadêmicos. Revista Ciências Sociais Unisinos, São Leopoldo, v. 53, p. 453-557, 2017.

BODART, C. das N.; TAVARES, C. dos S. Quando o assunto é Sociologia escolar: estado da arte nos periódicos de estratos superiores nas áreas de Ciências Sociais, Educação e Ensino. Revista de Ciências Sociais (UFC), Fortaleza, v. 51, n. 1, 2020.

BODART, C. das N.; TAVARES, C. dos S. Configurações territoriais dos cursos de formação de professores de Sociologia no Brasil (1934-2017): disputas e implicaçóes. Ciências Sociais Unisinos, São Leopoldo, v. 55, n. 2, 2019.

BODART, C. das N.; TAVARES, C. dos S. Programas de fomento à expansão do ensino superior e oferta dos cursos de Ciências Sociais no Brasil (1999-2017). Cadernos da Associaçáo Brasileira de Ensino de Ciências Sociais, Fortaleza, v. 2, n. 1. p. 07-29, jan./jul., 2018.

BOURDIEU, P. O campo científico. In: ORTIZ, R. (org.). Pierre Bourdieu: Sociologia. São Paulo: Ática, 1993. p. 122-155.

BRUNETTA, A. A.; CIGALES, M. P. Dossiês sobre ensino de Sociologia no Brasil (2007-2015): temáticas e autores(as). Latitude, Fortaleza, v. 12, n. 1, p. 148-171, 2018.

CHOPPIN, A. História dos livros e das ediçôes didáticas: sobre o estado da arte. Educação e Pesquisa, São Paulo, v. 30, n. 3, p. 549-566, set./dez. 2004.

ENGERROFF, A. M. B. Mapeando a produçáo sobre o livro didático de sociologia. 2017. 110 f. Trabalho de conclusão de curso (Graduação em Ciências Sociais) - Universidade Federal de Santa Catarina, Florianópolis, 2017.

ENGERROFF, A. M. B.; CIGALES, M.; THOLL, J. Quem conta a História do ensino de Sociologia no Brasil? Um estudo bibliométrico. Cadernos da Associaçáo Brasileira de Ensino de Ciências Sociais, Fortaleza, v. 1, n. 2, p. 65-87, 2017.

GOUlART, D. C.; SOUSA, D. T. de. O livro didático de Ciências Sociais, contribuiçóes e disputas na construçáo do campo de ensino de Ciências Sociais. In: 
CARUSO, H.; SANTOS, M. B. dos (org.). Rumos da Sociologia na educaçáo básica: ENESEB 2017, reformas, resistências e experiências de ensino. Porto Alegre: Cirkula, 2019. p. 147-157.

HANDFAS, A. O que temos pesquisado sobre os livros didáticos de sociologia? In: GONÇALVES, D. N.; MOCELIN, D. G.; MEIRELLES, M. (org.). Rumos da sociologia no ensino médio. Porto Alegre, Cirkula, 2016. p.131-142.

HANDFAS, A. O Estado da Arte do ensino de Sociologia na Educação Básica: Um levantamento preliminar da produçáo acadêmica. Revista Inter-Legere, Natal, v. 1, n. 9,23 out. 2011.

HANDFAS, A.; MAÇAIRA, J. P. O estado da arte da produção científica sobre o ensino de sociologia na educação básica. BIB, São Paulo, n. 74, p. 43-59, jul./dez. 2012. Publicado em julho de 2014.

HANDFAS, A. SANTOS, M. B. O livro didático de Sociologia em debate. In: GONÇALVES, D. N. (org.). Sociologia e juventude no ensino médio: formaçấo, PIBID e outras experiências. Campinas: Pontes, 2013. p. 75-86.

MACHADO, O. O ensino de ciências sociais na escola média. 1996. 199p. Dissertação (Mestrado em Educação) - Faculdade de Educação, Universidade de São Paulo, São Paulo, 1996.

MEUCCI, S. Notas sobre o pensamento social brasileiro nos livros didáticos de sociologia. Revista Brasileira de Sociologia, Porto Alegre, v.2, n.3, p. 209-232, jan./ jun. 2014.

MEUCCI, S. Institucionalizaçáo da sociologia no Brasil: primeiros manuais e cursos. São Paulo: Hucitec: Fapesp, 2011.

MEUCCI, S. Sobre a rotinização da sociologia no Brasil: os primeiros manuais didáticos, seus autores, suas expectativas. Mediaçóes, Londrina, v. 12, n. 1, p. 31-66, jan./jun. 2007.

MEUCCI, S. A institucionalizaçáo da sociologia no Brasil: os primeiros manuais e cursos. 2000. 158 f. Dissertação (Mestrado em Sociologia) - Instituto de Filosofia e Ciências Humanas, Universidade Estadual de Campinas, Campinas, 2000.

MOCELIN, D. G. O ensino de Sociologia e seu subcampo. In: BRUNETTA, A. A.; BODART, C. das N.; CIGALES, M. P. Dicionário do ensino de Sociologia. Maceió: Café com Sociologia, 2020. p. 397-401.

SARANDY, F. M. S. A Sociologia volta à escola: um estudo dos manuais de Sociologia para o ensino médio no Brasil. 2004. Dissertação (Mestrado em 
Sociologia) - Faculdade de Ciências Sociais, Universidade Federal do Rio de Janeiro, Rio de Janeiro, 2004.

Anexo 1 - Lista dos artigos científicos encontrados no levantamento, que tomam os manuais/livros didáticos de Sociologia como objeto ou fonte de pesquisa.

\begin{tabular}{|c|c|c|c|}
\hline Ano & Título & Revista & Autoria \\
\hline 2001 & $\begin{array}{l}\text { Os primeiros manuais didáticos de sociologia no } \\
\text { Brasil. }\end{array}$ & $\begin{array}{l}\text { Estudos de } \\
\text { Sociologia }\end{array}$ & Simone Meucci \\
\hline 2007 & $\begin{array}{l}\text { Sobre a rotinização da sociologia no Brasil: os pri- } \\
\text { meiros manuais didáticos, seus autores, suas expec- } \\
\text { tativas. }\end{array}$ & Mediaçóes & Simone Meucci \\
\hline 2010 & $\begin{array}{l}\text { A produção de manuais didáticos e o ensino de } \\
\text { Sociologia na escola média em dois momentos his- } \\
\text { tóricos (1935-1989). }\end{array}$ & $\begin{array}{l}\text { Revista HISTEDBR } \\
\text { On-Line }\end{array}$ & $\begin{array}{l}\text { Silvia Helena } \\
\text { Andrade de Brito }\end{array}$ \\
\hline 2010 & $\begin{array}{l}\text { O manual didático de sociologia e sociologia edu- } \\
\text { cacional: instrumento de formaçáo do professor } \\
(1923-1946) \text {. }\end{array}$ & $\begin{array}{l}\text { Revista HISTEDBR } \\
\text { On-line }\end{array}$ & $\begin{array}{l}\text { Maria Auxiliadora } \\
\text { Cavazotti }\end{array}$ \\
\hline 2012 & $\begin{array}{l}\text { O ensino de sociologia e a organizaçáo do trabalho } \\
\text { didático no Colégio Pedro II (1925-1945). }\end{array}$ & $\begin{array}{l}\text { Revista Brasileira } \\
\text { de História da } \\
\text { Educação }\end{array}$ & $\begin{array}{l}\text { Silvia Helena } \\
\text { Andrade Brito }\end{array}$ \\
\hline 2013 & $\begin{array}{l}\text { A Antropologia no Ensino Médio: uma análise a } \\
\text { partir dos livros didáticos. }\end{array}$ & $\begin{array}{l}\text { Cadernos de Estudos } \\
\text { Sociais }\end{array}$ & Amurabi Oliveira \\
\hline 2014 & $\begin{array}{l}\text { Dilemas da sociologia no Brasil: análise sobre os } \\
\text { manuais escolares de Amaral Fontoura e Fernando } \\
\text { de Azevedo. }\end{array}$ & Alabastro & Marcelo Cigales \\
\hline 2014 & $\begin{array}{l}\text { Os Movimentos Sociais no Livro Didático de Socio- } \\
\text { logia: Ensinar sobre a luta ou ensinar a lutar? }\end{array}$ & $\begin{array}{l}\text { Perspectiva } \\
\text { Sociológica } \\
\end{array}$ & $\begin{array}{l}\text { Vinícius Carvalho } \\
\text { Lima }\end{array}$ \\
\hline 2014 & $\begin{array}{l}\text { Notas sobre o pensamento social brasileiro nos livros } \\
\text { didáticos de sociologia. }\end{array}$ & $\begin{array}{l}\text { Revista Brasileira de } \\
\text { Sociologia-RBS }\end{array}$ & Simone Meucci \\
\hline 2014 & $\begin{array}{l}\text { Ideias pedagógicas de uma sociologia cristá: notas } \\
\text { sobre um compêndio de sociologia da década de } \\
1940 .\end{array}$ & $\begin{array}{l}\text { Revista HISTEDBR } \\
\text { On-line }\end{array}$ & Marcelo Cigales \\
\hline 2014 & $\begin{array}{l}\text { Sociologia na escola: A abordagem de temáticas clás- } \\
\text { sicas das ciências sociais nos livros didáticos. }\end{array}$ & $\begin{array}{l}\text { Saberes em } \\
\text { Perspectiva } \\
\end{array}$ & $\begin{array}{l}\text { Julia Polessa } \\
\text { Maçaira } \\
\end{array}$ \\
\hline 2015 & $\begin{array}{l}\text { A pesquisa como princípio pedagógico no ensino de } \\
\text { Sociologia: uma análise a partir dos livros seleciona- } \\
\text { dos no PNLD } 2015 \text {. }\end{array}$ & $\begin{array}{l}\text { Ciências Sociais } \\
\text { Unisinos }\end{array}$ & $\begin{array}{l}\text { Amurabi Oliveira } \\
\text { e Marcelo Pinheiro } \\
\text { Cigales }\end{array}$ \\
\hline 2015 & $\begin{array}{l}\text { Desafios de adoção do livro didático de sociologia e } \\
\text { formação continuada de professores. }\end{array}$ & Em Debate & $\begin{array}{l}\text { Thayene Gomes } \\
\text { Cavalcante e } \\
\text { Anicélia Ferreira } \\
\text { da Silva }\end{array}$ \\
\hline
\end{tabular}




\begin{tabular}{|c|c|c|c|}
\hline Ano & Título & Revista & Autoria \\
\hline 2015 & $\begin{array}{l}\text { O índio e o negro nos livros didáticos de Sociologia } \\
\text { adotados no PNLD. }\end{array}$ & $\begin{array}{l}\text { Revista Brasileira de } \\
\text { História \& Ciências } \\
\text { Sociais }\end{array}$ & $\begin{array}{l}\text { Erinaldo Ferreira } \\
\text { Carmo e Silas } \\
\text { Cassio Gomes } \\
\text { Nascimento }\end{array}$ \\
\hline 2015 & $\begin{array}{l}\text { A sociologia cristã e o pensamento de Alceu Amoroso } \\
\text { Lima em um colégio católico de formaçáo de profes- } \\
\text { soras em Santa Catarina. }\end{array}$ & $\begin{array}{l}\text { Revista Brasileira } \\
\text { de História da } \\
\text { Educação }\end{array}$ & $\begin{array}{l}\text { Maria das Dores } \\
\text { Daros e Elaine } \\
\text { Aparecida Teixeira } \\
\text { Pereira }\end{array}$ \\
\hline 2015 & $\begin{array}{l}\text { Raymond Murray e a Sociologia Católica no Brasil: } \\
\text { notas sobre um manual da década de } 1940 .\end{array}$ & $\begin{array}{l}\text { Revista Café com } \\
\text { Sociologia }\end{array}$ & Marcelo Cigales \\
\hline 2016 & $\begin{array}{l}\text { Interesses econômicos que incidem sobre o Programa } \\
\text { Nacional do Livro Didático (PNLD) de } 2012 \text { e o } \\
\text { guia do livro didático de Sociologia. }\end{array}$ & Criativa educativa & $\begin{array}{l}\text { Ricardo Pereira da } \\
\text { Silva }\end{array}$ \\
\hline 2016 & $\begin{array}{l}\text { Cidadania e ensino de sociologia nos manuais do } \\
\text { professor dos livros didáticos aprovados no PNLD } \\
2015 \text {. }\end{array}$ & $\begin{array}{l}\text { Estudos de } \\
\text { Sociologia }\end{array}$ & $\begin{array}{l}\text { Amurabi de } \\
\text { Oliveira e Ana } \\
\text { Martina Baron } \\
\text { Engerroff }\end{array}$ \\
\hline 2016 & $\begin{array}{l}\text { A Antropologia na educação básica: uma análise de } \\
\text { três livros didáticos. }\end{array}$ & $\begin{array}{l}\text { Perspectiva } \\
\text { Sociológica } \\
\end{array}$ & $\begin{array}{l}\text { Bárbara de Souza } \\
\text { Fontes }\end{array}$ \\
\hline 2016 & $\begin{array}{l}\text { Tramas discursivas presentes nos manuais didáticos } \\
\text { de sociologia aprovados no PNLD } 2012 .\end{array}$ & $\begin{array}{l}\text { Perspectiva } \\
\text { Sociológica } \\
\end{array}$ & $\begin{array}{l}\text { Luiz Felipe } \\
\text { Guimarães Bon }\end{array}$ \\
\hline 2016 & $\begin{array}{l}\text { A Sociologia no ensino médio: A temática dos } \\
\text { Direitos Humanos nos Livros Didáticos. }\end{array}$ & $\begin{array}{l}\text { Revista Café com } \\
\text { Sociologia }\end{array}$ & $\begin{array}{l}\text { Anderson Felipe } \\
\text { dos anjos Duarte }\end{array}$ \\
\hline 2016 & $\begin{array}{l}\text { O ensino de Sociologia: limites e possibilidades para } \\
\text { a efetivação da temática étnico-racial no livro didá- } \\
\text { tico. }\end{array}$ & Revista Inter-Legere & $\begin{array}{l}\text { Ana Carolina } \\
\text { Araújo de França }\end{array}$ \\
\hline 2016 & $\begin{array}{l}\text { Gênero e diversidade sexual em foco: avaliação dos } \\
\text { livros didáticos de Sociologia. }\end{array}$ & Revista Urutágua & $\begin{array}{l}\text { Marcela de } \\
\text { Oliveira Nunes } \\
\text { e Gabriella } \\
\text { Romagnoli Chagas }\end{array}$ \\
\hline 2017 & $\begin{array}{l}\text { Os livros didáticos de Sociologia e os sentidos do } \\
\text { ensino de Ciências Sociais na Educaçáo Básica. }\end{array}$ & $\begin{array}{l}\text { Cadernos da } \\
\text { Associaçáa Brasileira } \\
\text { de Ensino de } \\
\text { Ciências Sociais } \\
\end{array}$ & $\begin{array}{l}\text { Valci Melo Silva } \\
\text { dos Santos }\end{array}$ \\
\hline 2017 & $\begin{array}{l}\text { A pesquisa como ferramenta de ensino em sociolo- } \\
\text { gia: sentidos, obstáculos e potencialidades em livros } \\
\text { didáticos e em práticas docentes. }\end{array}$ & $\begin{array}{l}\text { Ciências Sociais } \\
\text { Unisinos }\end{array}$ & $\begin{array}{l}\text { David Gonçalves } \\
\text { Soares }\end{array}$ \\
\hline 2017 & $\begin{array}{l}\text { Gênero e sexualidade como temas da Sociologia } \\
\text { escolar: uma comparaçáo entre livros didáticos } \\
\text { (PNLD 2012 e 2015). }\end{array}$ & $\begin{array}{l}\text { Perspectiva } \\
\text { Sociológica }\end{array}$ & $\begin{array}{l}\text { Beatrice Cavalcante } \\
\text { Limoeiro }\end{array}$ \\
\hline 2017 & $\begin{array}{l}\text { Páginas contingentes: gênero e sexualidade no livro } \\
\text { didático da Sociologia hoje. }\end{array}$ & $\begin{array}{l}\text { Perspectiva } \\
\text { Sociológica }\end{array}$ & Diego Pontes \\
\hline
\end{tabular}




\begin{tabular}{|c|c|c|c|}
\hline Ano & Título & Revista & Autoria \\
\hline 2017 & $\begin{array}{l}\text { Representaçóes sobre arranjos familiares em livros de } \\
\text { Sociologia do Programa Nacional do Livro Didático } \\
\text { de } 2015 \text {. }\end{array}$ & $\begin{array}{l}\text { Teoria e Prática da } \\
\text { Educaçáo }\end{array}$ & $\begin{array}{l}\text { Angélica Gomes da } \\
\text { Silva Gouvêa e Jose } \\
\text { Jairo Vieira }\end{array}$ \\
\hline 2018 & $\begin{array}{l}\text { Gênero e sexualidades nos livros didáticos de } \\
\text { Sociologia aprovados pelo PNLD } 2015 .\end{array}$ & Revista Ártemis & $\begin{array}{l}\text { Diane Macedo, } \\
\text { Heloisa C. } \\
\text { Domingos, } \\
\text { Mariane S. Pisani, } \\
\text { Natan S. Kremer e } \\
\text { Rachel T. S. Abrão }\end{array}$ \\
\hline 2018 & $\begin{array}{l}\text { Os sentidos da sociologia escolar nos livros didáticos } \\
\text { no Brasil. }\end{array}$ & $\begin{array}{l}\text { Revista Pós-ciências } \\
\text { Sociais }\end{array}$ & $\begin{array}{l}\text { Ana Martina } \\
\text { Baron Engerroff e } \\
\text { Amurabi Oliveira }\end{array}$ \\
\hline 2019 & $\begin{array}{l}\text { A autonomia na mediação didática de professores } \\
\text { de Sociologia do Ensino Médio diante dos livros } \\
\text { didáticos. }\end{array}$ & $\begin{array}{l}\text { Cadernos da } \\
\text { Associação Brasileira } \\
\text { de Ensino de } \\
\text { Ciências Sociais }\end{array}$ & $\begin{array}{l}\text { Marcelo Sales } \\
\text { Galdino }\end{array}$ \\
\hline 2019 & $\begin{array}{l}\text { O conceito de Estado nos livros didáticos de socio- } \\
\text { logia para o ensino médio. }\end{array}$ & Colloquium Socialis. & $\begin{array}{l}\text { Renato Kendy } \\
\text { Hidaka e Rodrigo } \\
\text { Moreira Vieira } \\
\end{array}$ \\
\hline 2019 & $\begin{array}{l}\text { A presença da (Ciência) Politica e seus conceitos nos } \\
\text { Livros Didáticos de Sociologia no PNLD } 2015 .\end{array}$ & Em tese & $\begin{array}{l}\text { Guilherme } \\
\text { Fernando } \\
\text { Schnekenberg e } \\
\text { Maria Aparecida } \\
\text { Bridi } \\
\end{array}$ \\
\hline 2019 & $\begin{array}{l}\text { A sociologia católica de Francisca Peeters na cons- } \\
\text { tituiçáo do campo educacional brasileiro na década } \\
\text { de } 1930 .\end{array}$ & Em tese & Marcelo Cigales \\
\hline 2019 & $\begin{array}{l}\text { As Ciências Sociais e os manuais escolares: depen- } \\
\text { dência mútua e responsabilidade social. }\end{array}$ & Em tese & $\begin{array}{l}\text { Kira Mahamud } \\
\text { Ângulo e Ana } \\
\text { Martina Baron } \\
\text { Engerroff } \\
\end{array}$ \\
\hline 2019 & $\begin{array}{l}\text { Gênero e currículo: olhares do feminismo negro e } \\
\text { decolonial sobre um livro didático de Sociologia. }\end{array}$ & Em tese & $\begin{array}{l}\text { Marcia Menezes } \\
\text { Thomaz Pereira }\end{array}$ \\
\hline 2019 & $\begin{array}{l}\text { Manuais didáticos e currículo de sociologia: uma } \\
\text { análise pós-estruturalista. }\end{array}$ & Em tese & $\begin{array}{l}\text { Jefferson Evanio } \\
\text { da Silva e Joanildo } \\
\text { Albuquerque } \\
\text { Burity }\end{array}$ \\
\hline 2019 & $\begin{array}{l}\text { O conceito de classe: os livros didáticos de sociologia } \\
\text { e a proposta de EP Thompson. }\end{array}$ & Em tese & $\begin{array}{l}\text { Kênia Mara } \\
\text { Gaedtke }\end{array}$ \\
\hline 2019 & $\begin{array}{l}\text { Os manuais de Sociologia Educacional nos anos } \\
\text { de 1940: contexto de produçáo, autores, estruturas } \\
\text { didáticas e perspectivas teóricas. }\end{array}$ & Em tese & $\begin{array}{l}\text { Cristiano das } \\
\text { Neves Bodart e } \\
\text { Ewerton Diego de } \\
\text { Souza }\end{array}$ \\
\hline
\end{tabular}




\begin{tabular}{|c|c|c|c|}
\hline Ano & Título & Revista & Autoria \\
\hline 2019 & $\begin{array}{l}\text { Para entender sociologia: os manuais escolares de } \\
\text { Maria Olga Mattar. }\end{array}$ & Em tese & $\begin{array}{l}\text { Patrícia dos Santos } \\
\text { Dotti do Prado }\end{array}$ \\
\hline 2019 & $\begin{array}{l}\text { O gênero como conteúdo escolar da Sociologia: uma } \\
\text { análise dos livros didáticos de Sociologia do PNLD } \\
2018 \text {. }\end{array}$ & $\begin{array}{l}\text { Perspectiva } \\
\text { Sociológica }\end{array}$ & $\begin{array}{l}\text { Caroline Souza } \\
\text { Castro }\end{array}$ \\
\hline 2019 & $\begin{array}{l}\text { A reação católica e a formaçáo de professores } \\
\text { no Brasil: os manuais disciplinares: Noçôes de } \\
\text { Sociologia e Educação. }\end{array}$ & $\begin{array}{l}\text { Revista Brasileira } \\
\text { de História da } \\
\text { Educação }\end{array}$ & $\begin{array}{l}\text { Sandra Maria de } \\
\text { Oliveira e Décio } \\
\text { Gatti Júnior }\end{array}$ \\
\hline 2019 & $\begin{array}{l}\text { Leviatá para jovens? O conceito de Estado nos livros } \\
\text { didáticos de Sociologia. }\end{array}$ & $\begin{array}{l}\text { Revista } \\
\text { Interdisciplinar } \\
\text { em Estudos de } \\
\text { Linguagem }\end{array}$ & $\begin{array}{l}\text { André Rocha } \\
\text { Santos e Alessa } \\
\text { Coelho Lauriano }\end{array}$ \\
\hline 2019 & $\begin{array}{l}\text { A (Ciência) Política como saber escolar e os livros } \\
\text { didáticos de Sociologia do PNLD } 2015 .\end{array}$ & Sociologias Plurais & GF Schnekenberg \\
\hline 2019 & $\begin{array}{l}\text { Implementação do Plano Nacional do Livro } \\
\text { Didático: docentes de Sociologia e os usos do Livro } \\
\text { Didático no Nordeste brasileiro. }\end{array}$ & Sociologias Plurais & Laís Celis Merissi \\
\hline 2020 & $\begin{array}{l}\text { A formação de professores primários e as disputas } \\
\text { ideológicas em manuais escolares de Sociologia da } \\
\text { Educação (1930-1950). }\end{array}$ & $\begin{array}{l}\text { Cadernos da } \\
\text { Associação Brasileira } \\
\text { de Ensino de } \\
\text { Ciências Sociais }\end{array}$ & $\begin{array}{l}\text { Elizandra Cristina } \\
\text { Rodrigues da Silva } \\
\text { e Cristiano das } \\
\text { Neves Bodart } \\
\end{array}$ \\
\hline 2020 & $\begin{array}{l}\text { A temática indígena nos livros didáticos de } \\
\text { Sociologia. }\end{array}$ & $\begin{array}{l}\text { Perspectiva } \\
\text { Sociológica }\end{array}$ & $\begin{array}{l}\text { Ellen Fernanda } \\
\text { Araújo }\end{array}$ \\
\hline 2020 & O senso comum em livros didáticos de Sociologia. & $\begin{array}{l}\text { REVES - Revista } \\
\text { Relaçốes Sociais }\end{array}$ & $\begin{array}{l}\text { Ricardo Cortez } \\
\text { Lopes }\end{array}$ \\
\hline 2020 & $\begin{array}{l}\text { Os livros didáticos da perspectiva da Sociologia do } \\
\text { Conhecimento: uma proposição teórico-metodoló- } \\
\text { gica. }\end{array}$ & $\begin{array}{l}\text { Revista Brasileira } \\
\text { de História da } \\
\text { Educação }\end{array}$ & Simone Meucci \\
\hline 2020 & $\begin{array}{l}\text { A História e a cultura africana em Sociologia: as reli- } \\
\text { giooses de matriz africana. }\end{array}$ & $\begin{array}{l}\text { Revista Relegens } \\
\text { Thréskeia }\end{array}$ & Tamara Vieira \\
\hline 2020 & $\begin{array}{l}\text { O tema do refúgio nos livros didáticos de Sociologia } \\
\text { aprovados no PNLD } 2018 .\end{array}$ & Teoria e Cultura & $\begin{array}{l}\text { Fernanda Di Flora } \\
\text { e Beatriz de Melo } \\
\text { Silva }\end{array}$ \\
\hline 2020 & $\begin{array}{l}\text { A noção de gênero nos livros didáticos de Sociologia } \\
\text { para o ensino médio. }\end{array}$ & $\begin{array}{l}\text { Interfaces } \\
\text { Científicas -Educação }\end{array}$ & $\begin{array}{l}\text { Renato Kendy } \\
\text { Hidaka e Gabriela } \\
\text { Sebba Abdo }\end{array}$ \\
\hline
\end{tabular}

Fonte: Elaboração própria, com base em levantamento realizado no Google Scholar, em 30 dez. 2020.

Recebido em: 19 de julho de 2021.

Aprovado em: 16 de setembro de 2021. 